Aquatic Plant Control Research Program

\title{
Geospatial Assessments of Phragmites australis Die-Off in South Louisiana: Preliminary Findings
}

Glenn M. Suir, Christina L. Saltus, and Molly K. Reif

August 2018

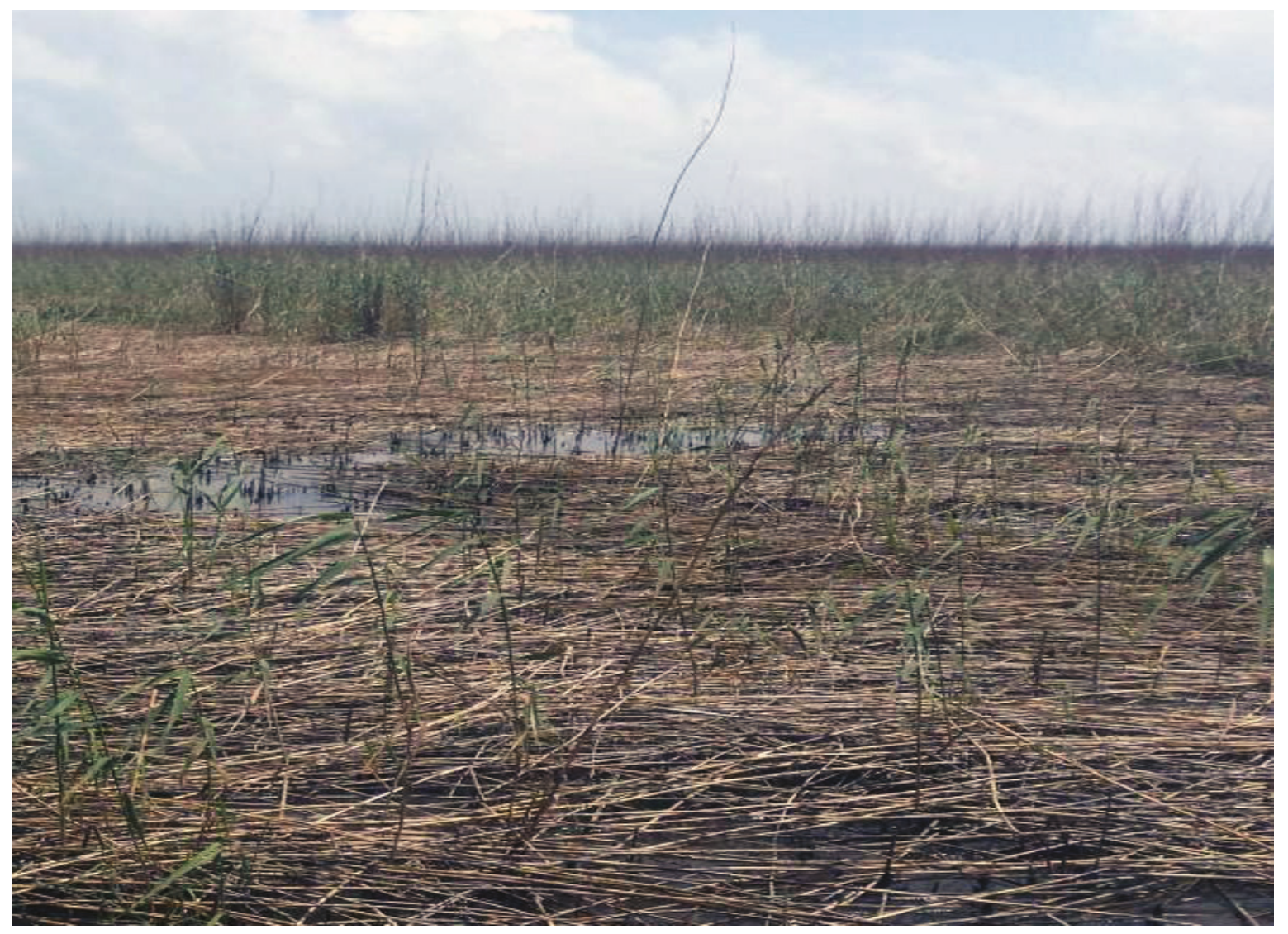


The U.S. Army Engineer Research and Development Center (ERDC) solves the nation's toughest engineering and environmental challenges. ERDC develops innovative solutions in civil and military engineering, geospatial sciences, water resources, and environmental sciences for the Army, the Department of Defense, civilian agencies, and our nation's public good. Find out more at www.erdc.usace.army.mil.

To search for other technical reports published by ERDC, visit the ERDC online library at http://acwc.sdp.sirsi.net/client/default. 


\title{
Geospatial Assessments of Phragmites australis Die-Off in South Louisiana: Preliminary Findings
}

\author{
Glenn M. Suir \\ Environmental Laboratory \\ U.S. Army Engineer Research and Development Center \\ 646 Cajundome Blvd., Suite 301 \\ Lafayette, LA 70506 \\ Christina L. Saltus \\ Environmental Laboratory \\ U.S. Army Engineer Research and Development Center \\ Wetlands and Environmental Technologies Research Facility \\ Louisiana State University - Military Sciences Building \\ Baton Rouge, LA 70803 \\ Molly K. Reif \\ Environmental Laboratory \\ U.S. Army Engineer Research and Development Center \\ Joint Airborne Lidar Bathymetry Technical Center of Expertise \\ Kiln, MS 39556
}

Final report

Approved for public release; distribution is unlimited.

\author{
Prepared for U.S. Army Corps of Engineers \\ Washington, DC 20314-1000 \\ Under Project No. 462030, “Aquatic Plant Control Research Program”
}




\section{Abstract}

The Lower Mississippi River Delta (MRD) is dominated by Phragmites australis which provides a stabilizing force, protecting marsh communities from erosion and storm-related impacts. Starting in 2016, massive die-offs of Phragmites were first observed in the MRD coinciding with observations of Nipponaclerda biwakoensis (Phragmites scale), an exotic insect originating from Asia. Concurrent with the insect invasion, many previously healthy stands have died or experienced stunted growth, resulting in conversion to understory species or to open water features. This study utilized remote sensing methods to assess vegetation in scaleimpacted areas of the MRD. The Normalized Difference Vegetation Index (NDVI) was used to evaluate historical changes in vegetation health, and species classifications were used to discriminate Phragmites from nontarget species to better understand vegetation impacts, especially in cases where Phragmites haplotype impacts may have differed. Moderate spatial resolution NDVI analyses provided rapid and cursory examinations of vegetation health while a proof of concept approach for differentiating Phragmites haplotypes and other species provided a preliminary way to assess potential species-specific stress or injury. These preliminary data show that extensive areas of Phragmites stands in the MRD were severely impacted (potentially by the scale) and some Phragmites haplotypes were more susceptible than others.

DISCLAIMER: The contents of this report are not to be used for advertising, publication, or promotional purposes. Citation of trade names does not constitute an official endorsement or approval of the use of such commercial products. All product names and trademarks cited are the property of their respective owners. The findings of this report are not to be construed as an official Department of the Army position unless so designated by other authorized documents. 


\section{Contents}

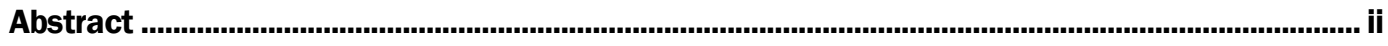

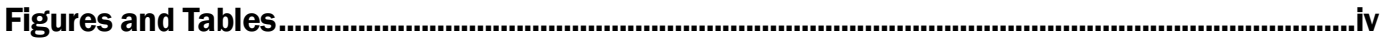

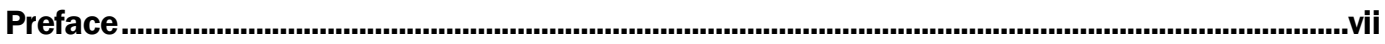

1 Introduction ................................................................................................................................ 1

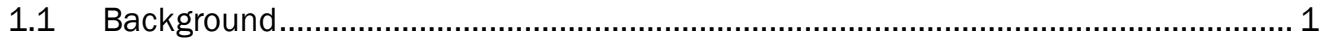

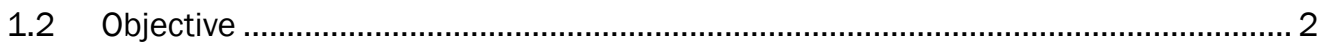

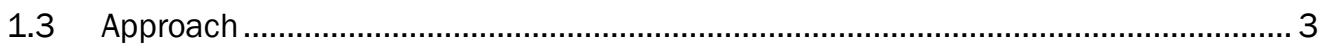

2 Methods ..................................................................................................................................... 5

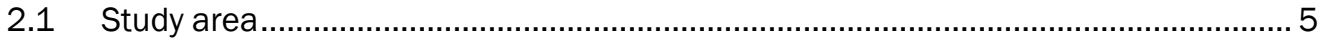

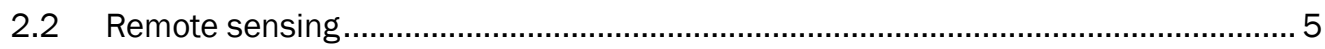

2.2.1 Data acquisition and processing.................................................................... 5

2.2.2 Normalized Difference Vegetation Index (NDVI)............................................... 6

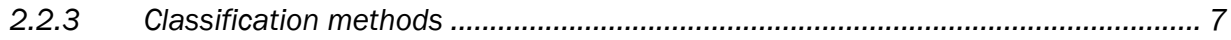

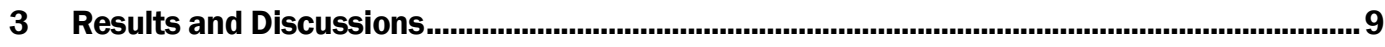

3.1 Moderate resolution data ............................................................................ 9

3.2 High-resolution data .............................................................................. 12

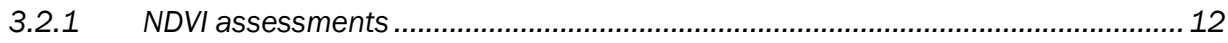

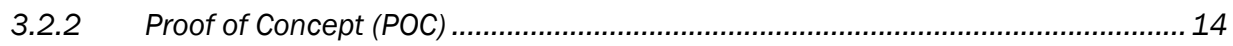

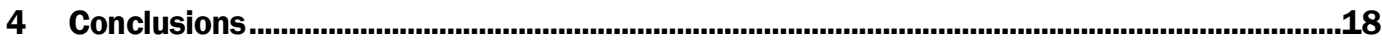

References ....................................................................................................................................20

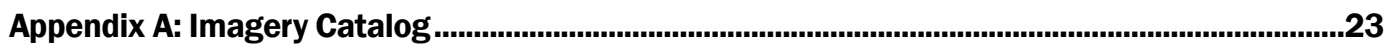

Appendix B: Landsat-Derived NDVI...........................................................................................24

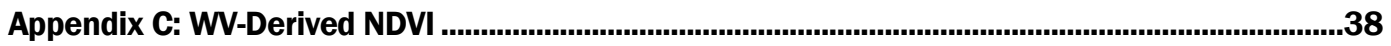

\section{Report Documentation Page}




\section{Figures and Tables}

\section{Figures}

Figure 1. Phragmites scale distribution map (left panel) and study site (right panel) POC area (dark gray polygon) and areas of interest (AOI) (white boundaries) within the MRD (black boundary).

Figure 2. October 2015 Landsat-8-derived NDVI of vegetation within the MRD and project $\mathrm{AOI}$; red areas indicate vegetation with low plant vigor while green areas indicate healthy vegetation.

Figure 3. October 2016 Landsat-8-derived NDVI of vegetation within the MRD and project AOl; red areas indicate vegetation with low plant vigor while green areas indicate healthy vegetation

Figure 4. Change analysis based on Landsat-8 derived NDVI of vegetation within the MRD from October 2015 to October 2016; green-blue color ramp represents increasing NDVI values, and the yellow-orange-red colors represent decreasing NDVI values.

Figure 5. Graph showing mean NDVI trajectories for all Landsat-derived data points in the MRD, Main Pass, Pass a Loutre, South Pass, and Southwest Pass assessment units

Figure 6. November $14 \mathrm{WV}$-derived NDVI of vegetation within the MRD and project AOI; red areas indicate vegetation with low plant vigor while green areas indicate healthy vegetation

Figure 7. October 2016 WV-derived NDVI of vegetation within the MRD and project AOI; red areas indicate vegetation with low plant vigor while green areas indicate healthy vegetation

Figure 8. Change analysis based on WV-derived NDVI of vegetation within the Pass a Loutre AOI from November 2014 to October 2016; green-blue color ramp represents increasing NDVI values, and the yellow-orange-red colors represent decreasing NDVI values.

Figure 9. WV3 satellite image (color infrared composite) of the POC area (top image) acquired on 1 October 2016 and the derived classification image (bottom image).

Figure B-1. March 2008 Landsat-8-derived NDVI of vegetation within the Mississippi River Delta and project AOI.

Figure B-2. October 2008 Landsat-8-derived NDVI of vegetation within the Mississippi River Delta and project AOI.

Figure B-3. January 2009 Landsat-8-derived NDVI of vegetation within the Mississippi

River Delta and project AOI.

Figure B-4. July 2009 Landsat-8-derived NDVI of vegetation within the Mississippi River Delta and project AOI.

Figure B-5. October 2009 Landsat-8-derived NDVI of vegetation within the Mississippi River Delta and project AOI.

Figure B-6. February 2010 Landsat-8-derived NDVI of vegetation within the Mississippi River Delta and project AOI.

Figure B-7. September 2010 Landsat-8-derived NDVI of vegetation within the Mississippi River Delta and project AOI.

Figure B-8. March 2011 Landsat-8-derived NDVI of vegetation within the Mississippi River Delta and project $\mathrm{AOI}$. 
Figure B-9. April 2011 Landsat-8-derived NDVI of vegetation within the Mississippi River Delta and project AOI.

Figure B-10. June 2011 Landsat-8-derived NDVI of vegetation within the Mississippi River Delta and project AOI.

Figure B-11. September 2011 Landsat-8-derived NDVI of vegetation within the Mississippi River Delta and project AOI.

Figure B-12. December 2013 Landsat-8-derived NDVI of vegetation within the Mississippi

River Delta and project AOI.

Figure B-13. April 2014 Landsat-8-derived NDVI of vegetation within the Mississippi River Delta and project AOI.

Figure B-14. November 2014 Landsat-8-derived NDVI of vegetation within the Mississippi

River Delta and project AOI.

Figure B-15. January 2015 Landsat-8-derived NDVI of vegetation within the Mississippi River Delta and project AOI.

Figure B-16. August 2015 Landsat-8-derived NDVI of vegetation within the Mississippi

River Delta and project AOI.

Figure B-17. January 2016 Landsat-8-derived NDVI of vegetation within the Mississippi

River Delta and project AOI.

Figure B-18. February 2016 Landsat-8-derived NDVI of vegetation within the Mississippi

River Delta and project AOI.

Figure B-19. March 2016 Landsat-8-derived NDVI of vegetation within the Mississippi

River Delta and project AOI.

Figure B-20. March 2017 Landsat-8-derived NDVI of vegetation within the Mississippi

River Delta and project AOI.

Figure B-21. Change analysis based on Landsat-8 derived NDVI of vegetation within the MRD from October 2008 to October 2009.

Figure B-22. Change analysis based on Landsat-8 derived NDVI of vegetation within the MRD from October 2009 to September 2010.

Figure B-23. Change analysis based on Landsat-8 derived NDVI of vegetation within the MRD from September 2010 to September 2011.

Figure B-24. Change analysis based on Landsat-8 derived NDVI of vegetation within the MRD from September 2011 to December 2013.

Figure B-25. Change analysis based on Landsat-8 derived NDVI of vegetation within the MRD from December 2013 to November 2014.

Figure B-26. Change analysis based on Landsat-8 derived NDVI of vegetation within the MRD from November 2014 to October 2015.

Figure B-27. Change analysis based on Landsat-8 derived NDVI of vegetation within the MRD from March 2016 to March 2017.

Figure C-1. October 2012 WV-derived NDVI of vegetation within the Pass a Loutre project area.

Figure C-2. August 2017 WV-derived NDVI of vegetation within the Pass a Loutre project area.

Figure C-3. Change analysis based on WV-derived NDVI of vegetation within the Pass a Loutre assessment area from October 2012 to November 2014.

Figure C-4. Change analysis based on WV-derived NDVI of vegetation within the Pass a Loutre assessment area from October 2016 to August 2017. 


\section{Tables}

Table 1. The remote sensing platforms utilized in this study. (courtesy of Allen and Suir

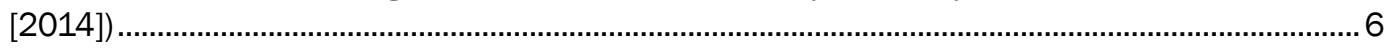

Table 2. Classification accuracy assessment listing the total number of assessment sample points per class, the accuracy percentage of the classification per class, and the percentage of total POC AOI area for each class.

Table A-1. Catalog of moderate (white cells) and high resolution (grey cells) imagery for the MRD, Southwest Pass (SW), South Pass (S), Pass a Loutre (Loutre), and Main Pass

(Main) assessment units... 


\section{Preface}

The work reported herein was conducted as part of the Aquatic Plant Control Research Program (APCRP), Project No. 462030. The APCRP is sponsored by Headquarters, U.S. Army Corps of Engineers (HQUSACE), and is assigned to the U.S. Army Engineer Research and Development Center (ERDC) under the purview of the Environmental Laboratory (EL), Vicksburg, MS. The APCRP is managed under the Civil Works Environmental Engineering and Sciences Office, Dr. Alfred F. Cofrancesco, Technical Director. Dr. Linda S. Nelson was Program Manager of the APCRP. Program Monitor during this study was Jeremy Crossland, HQUSACE.

The authors express appreciation to Ms. Jennifer Laird and Dr. Todd Swannack for review of the paper and to Dr. Rodrigo Diaz and Dr. James Cronin for technical and field assistance for this project.

Support and cooperation for this work were provided by the following:

- Louisiana State University, Department of Entomology

- U.S. Geological Survey, Wetland and Aquatic Research Center.

This work was performed under the general supervision of Dr. Ilker Adiguzel, Director, EL; Mr. Mark Farr, Chief, Ecosystem Evaluation and Engineering Division; and Mr. Mark Graves, Chief, Environmental Systems Branch.

COL Ivan P. Beckman was Commander of ERDC, and Dr. David W. Pittman was Director of ERDC. 


\section{Unit Conversion Factor}

\begin{tabular}{|l|l|l|}
\hline Multiply & By & To Obtain \\
\hline miles (U.S. statute) & $1,609.347$ & meters \\
\hline
\end{tabular}




\section{Introduction}

\subsection{Background}

Extensive injury and die-off of Phragmites australis (common reed) have recently been observed in the Mississippi River Delta (MRD) in south Louisiana, prompting the investigation of impacts associated with the infestation of the exotic Nipponaclerda biwakoensis (Kuwana) insect. This research focused on the evaluation of moderate and high-resolution satellite imagery and techniques to quantify and monitor conditions of impacted plant communities. Specifically, it included a time series of plant health as well as a proof of concept (POC) to differentiate target Phragmites haplotypes from non-target plant species. The development and advancement of these techniques provide means for rapid tracking of areal extent and severity of vegetation impacts and ultimately provides decision support information to enhance pest and resource management.

Since the 1930s, the Louisiana MRD has experienced dramatic loss of wetlands and significant reductions in ecosystem goods and services (Day et al. 2000; Couvillion et al. 2011; Suir et al. 2014). The loss of wetland structure, function, and services are due in large part to a complex interaction of spatial and temporal factors, including reduced riverine inputs, flood control measures, altered wetland hydrology, saltwater intrusion, subsidence, wave erosion, reduced river sediment load, and sealevel rise (Day et al. 2000). These conditions have resulted, in part, in the expansion of Phragmites australis, which now dominates approximately two-thirds of the low-relief exterior marshes of the MRD (Hauber et al. 2011). The monotypic stands of Phragmites have played a major role in stabilizing the outer reaches of the MRD, thereby buffering and protecting the more diverse and susceptible interior marsh communities (Coleman et al. 1998; Hauber et al. 2011). There are four haplotypes of Phragmites australis in the MRD. These include the introduced Delta haplotype (North African origin), which is the most abundant in the MRD; the introduced Greeny haplotype (European origin); the invasive European haplotype (European/Asian origin); and the Gulf haplotype (Central and South American origin) (Hauber et al. 2011; Lambertini et al. 2012). Differences in haplotype morphology and anatomy, as well as physiological tolerances, are of major concern since they could have significant implications on long-term ecosystem resilience and function 
(Saltonstall 2002; Howard et al. 2008; Meyerson et al. 2010). Though previous studies have evaluated Phragmites expansion, recovery, and salinity tolerance, few have evaluated and compared the impacts of biotic stressors (i.e., predation, disease, allelopathy, and parasitism) on Phragmites haplotypes (Chabreck and Palmisano 1973; Burdick and Konisky 2003; Achenbach and Brix 2014).

\subsection{Objective}

During the summer of 2016, Nipponaclerda biwakoensis (Phragmites scale), an exotic insect native to China and Japan (McConnell 1954), was first observed on Phragmites plants in the MRD (Figure 1). This insect, which settles on stems of Phragmites, can injure or kill the plant by extracting its sap; in large numbers the insect can deplete the plant's energy reserves (Kaneko et al. 2004; Diaz et al. 2017). Preliminary aerial and ground-based surveys were conducted by Louisiana State University (LSU) to evaluate the occurrence and distribution of Phragmites scale and Phragmites australis injury throughout southeast coastal Louisiana. These surveys showed an outbreak of the exotic insect and a distribution of Phragmites scale beyond the MRD and into portions of the Deltaic Plain (Figure 1). The surveys also identified other possible stressors (i.e., plant pathogens, sediment toxins, changes in salinity, and high water levels) that may be impacting Phragmites australis populations. Preliminary observations also indicated that Phragmites haplotypes differ in their tolerance to these stressors. However, these differences have not previously been observed or examined (Diaz et al. 2017). Therefore, the objectives of this study were to (1) evaluate the use of moderate and high spatial resolution satellite imagery to quantify vegetation biomass as a means of monitoring vegetation health within the MRD; (2) evaluate the use of high spatial resolution satellite imagery in a POC approach for differentiating Phragmites haplotypes from other plant species and species/haplotype-level injury; and (3) provide products (i.e., maps, data, and reports) to support decision making for pest control, navigation, and ecosystem management. 
Figure 1. Phragmites scale distribution map (left panel) and study site (right panel) POC area (dark gray polygon) and areas of interest (AOI) (white boundaries) within the MRD

(black boundary).

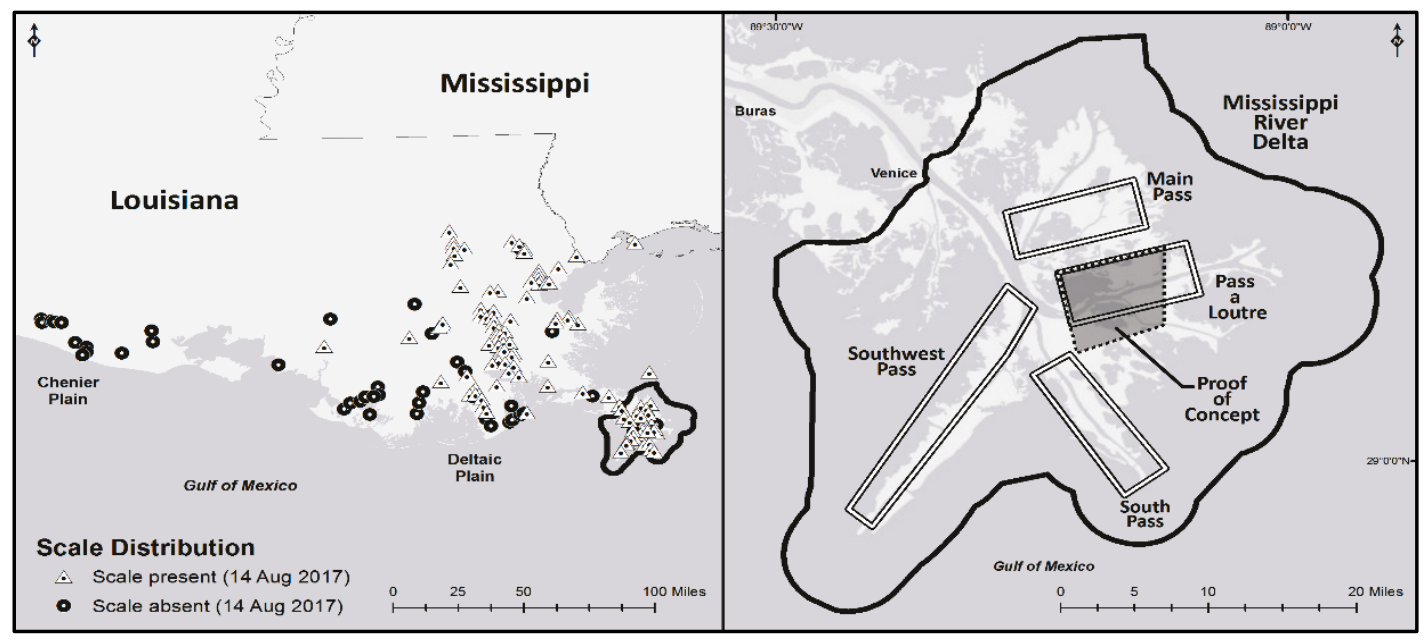

\subsection{Approach}

Traditionally, field assessments like those performed in the preliminary surveys by LSU have been used to monitor infestations and conditions in coastal wetlands (Cardoch et al. 2002). However, in situ measurements of condition, function, and sustainability across large geographic areas can be impractical. Remote sensing data and techniques provide tools that are beneficial for landscape analyses because they supply metrics for detecting, quantifying, and monitoring coastal ecosystem structure and function at a multitude of spatial, spectral, and temporal scales. The Normalized Difference Vegetation Index (NDVI) is a primary measure of condition, function, recovery, and sustainability. Since the NDVI has traditionally been used to assess impacts from anthropogenic, natural, and invasive disturbances (An et al. 2013; Bianchette et al. 2009; Couvillion and Beck 2013; Klemas 2013; Steyer et al. 2013), it was used in this study as a measure of primary productivity and plant vigor.

The detection and classification of coastal wetland features utilizing satellite imagery is a standard approach for assessing expansive areas where ground-based survey methods would be costly and time prohibitive (Lane et al. 2015; McCarthy et al. 2015; Suir et al. 2011). In particular, the use of high-resolution satellite imagery, such as those collected from the WorldView (WV) satellite series, provides the advantage of increased spatial and spectral capability that is crucial for differentiating species in a coastal ecosystem (Suir et al. 2018). Previous studies have utilized highresolution spatial and spectral imagery, ground-based survey data, and a 
combination of image classification techniques (i.e., spectral indices and supervised/unsupervised) to differentiate wetland plant species in areas of rapid change (Lane et al. 2015; McCarthy et al. 2015; Rapinel et al. 2014). Similar approaches, using WV imagery, ground, and other ancillary data, were evaluated in a POC (Figure 1). 


\section{Methods}

\subsection{Study area}

The preliminary ground surveys were used to identify regions experiencing the most severe impacts. The impacted regions, which are dominated by the Delta haplotype, exhibited either stunted growth (e.g., reduced height with symptoms of chlorosis and browning); lodged dead stems; or converted to open water. The preliminary surveys also showed these hotspots were along four primary waterways in the MRD. The regions of high impact were used to establish AOI for this study (Figure 1), and they include the MRD (also known as the Bird's Foot or Plaquemines-Balize Delta) and four primary AOIs: Southwest Pass, South Pass, Pass a Loutre, and Main Pass (Figure 1). In addition, a POC AOI (within the Pass a Loutre AOI) was established based on image availability, presence of Phragmites haplotypes and non-target plant species (e.g., floating and submerged aquatics, shrub and woody vegetation), and supplemental ground data collected by LSU (Figure 1).

\subsection{Remote sensing}

\subsubsection{Data acquisition and processing}

The remote sensing assessments were performed using moderateresolution satellite imagery (i.e., Landsat, 2008 to 2017) for all AOIs and high-resolution satellite imagery (i.e., WV, 2012 to 2017) for specific areas of concern. Sensor specifications are provided in Table 1 (Allen and Suir 2014). Landsat Thematic Mapper (TM) satellite imagery provides moderate spatial (28-meter) and temporal (16-day return) resolution data that are useful for estimating short-term landscape variation linked to disturbance events and/or prevailing environmental conditions (Suir et al. 2011). Landsat data sets were acquired using the Google Earth Engine (GEE) service, which provides a platform for planetary-scale environmental data analysis using historical and current global satellite imagery. GEE utilizes its image collection to apply radiometric, atmospheric, and geometric corrections and creates image composites by using pixel median values to remove outliers (i.e., cloud cover from neighboring scenes) (Strahler et al. 1999; Chander et al. 2009). The WorldView-2 (WV2; 46 centimeter [cm] panchromatic and $185 \mathrm{~cm}$ multispectral, launched 2009) and WorldView-3 (WV3; $31 \mathrm{~cm}$ panchromatic and $124 \mathrm{~cm}$ multispectral, launched 2014) sensors are the 
most spectrally diverse commercial satellites available. Archived data from these sensors, which collect eight multispectral bands (coastal, yellow, blue, green, red, red edge, near-infrared 1, and near-infrared 2 [NIR2]), were acquired using the DigitalGlobe Enhanced Viewer Web Hosting Service. ENVI version 5.4.1 (Exelis Visual Information Solutions, Boulder, $\mathrm{CO}$ ) was used to radiometrically and atmospherically correct all satellite data. This process consists of transforming digital numbers to spectral radiance values at top of atmosphere (TOA) and then transforming radiance into TOA reflectance by applying corrections for solar illumination geometry (Strahler et al. 1999; Chander et al. 2009; Tarantino et al. 2012).

Table 1. The remote sensing platforms utilized in this study. (courtesy of Allen and Suir [2014])

\begin{tabular}{|c|c|c|c|c|c|c|c|}
\hline \multirow[b]{2}{*}{ Satellite/Sensor } & \multirow[b]{2}{*}{ Spectral Bands } & \multicolumn{2}{|c|}{$\begin{array}{l}\text { Spatial Resolution } \\
(\mathrm{m})^{*}\end{array}$} & \multirow{2}{*}{$\begin{array}{l}\text { Swath } \\
\text { Width } \\
(\mathrm{km})^{* *}\end{array}$} & \multirow{2}{*}{$\begin{array}{l}\text { Repeat } \\
\text { Orbit } \\
\text { (days) }\end{array}$} & \multirow[b]{2}{*}{ Taskable } & \multirow[b]{2}{*}{ Availability } \\
\hline & & Pan & Multispectral & & & & \\
\hline $\begin{array}{l}\text { Landsat } 5 \\
\text { TM/MSS }\end{array}$ & $\begin{array}{l}6 \text { multispectral + } \\
\text { pan + thermal }\end{array}$ & 15 & 30 & 185 & 16 & $N$ & Free \\
\hline $\begin{array}{l}\text { Landsat } 8 \\
\text { (Feb 2013) }\end{array}$ & $\begin{array}{l}6 \text { multispectral + } \\
\text { pan + thermal }\end{array}$ & 15 & 30 & 185 & 16 & $N$ & Free \\
\hline $\begin{array}{l}\text { Digital Globe } \\
\text { WorldView-2 }\end{array}$ & $\begin{array}{l}8 \text { multispectral + } \\
\text { pan }\end{array}$ & 0.46 & 1.8 & 16.4 & 1 & $Y$ & cost / AGC \\
\hline $\begin{array}{l}\text { Digital Globe } \\
\text { WorldView-3 }\end{array}$ & $\begin{array}{l}8 \text { multispectral + } \\
\text { pan }+ \text { SWIR/CAVIS }\end{array}$ & 0.31 & 1.24 & 13.1 & 1 & $Y$ & cost / AGC \\
\hline
\end{tabular}

*meter

$* *$ kilometer

\subsubsection{Normalized Difference Vegetation Index (NDVI)}

NDVI values were calculated on all moderate- and high-resolution imagery using the standard equation (Rouse et al. 1974):

$$
\mathrm{NDVI}=\frac{\mathrm{NIR}-\mathrm{Red}}{\mathrm{NIR}+\mathrm{Red}}
$$

This equation utilizes a band ratio of satellite imagery between a nearinfrared (NIR) and red band to measure an ecosystem's ability to capture solar energy and convert it to organic carbon or biomass (An et al. 2013). Since healthy green vegetation absorbs light in the red portion of the light spectrum and reflects light in the NIR portion of the spectrum, the NDVI has well-established correlations to photosynthetic activity, aboveground biomass, and leaf area index (Carle 2013). The NIR2 band was utilized for 
all WV-derived NDVI data. The NIR2 band contains atmospheric absorption properties that enable the index to better detect the spectral signatures of floating and submerged aquatic vegetation.

Optical inspections were performed on all scenes and composites to identify and remove satellite images of poor quality. All non-wetland vegetation and newly constructed restoration (Beneficial Use of Dredged Material at Pass a Loutre) features within the MRD were excluded from each satellite image. NDVI values less than zero $(<0)$ are typical of non-vegetation features (e.g., water, cloud, impervious surfaces) (Reif et al. 2011; Carle 2013) and were also excluded from each image. Since floating and rooted aquatic vegetation are common in the MRD, a frequency function was used to exclude all remaining water and areas with intermittent vegetation (pixels that were classified as land in $<50 \%$ of all images; i.e., floating aquatics). ESRI ArcGIS version 10.5 (Redlands, CA: Environmental Systems Research Institute) was used to calculate zonal statistics (i.e., mean value) for all Landsatderived NDVI images using the MRD and AOI assessment boundaries. Relative changes in NDVI values were determined over a period of interest for each AOI, in which values from a later date were subtracted from an earlier date.

\subsubsection{Classification methods}

The POC approach for differentiating target Phragmites haplotypes from non-target plant species using high spatial resolution satellite imagery was accomplished through a hybrid approach. This approach utilized spectral indices and pixel-based classification methods informed by ground and aerial survey data as well as high-resolution aerial photography and satellite imagery. Two cloud-free WV3 satellite images collected on 1 October 2016 were used for vegetation classification. Prior to classification, the images were radiometrically calibrated and atmospherically corrected, then mosaicked and color balanced in ENVI 5.4.1. In August and September of 2017, LSU scientists performed two POC ground-based surveys. These surveys, which identified two Phragmites haplotypes (Delta and European) within the POC AOI, were used to evaluate methods capable of detecting Phragmites haplotypes. In addition, ancillary data (i.e., unmanned aircraft system-based video [11-12 October 2016], National Agriculture Imagery Program aerial photography [2 May 2015], WV2 and WV3 imagery [26 October 2014, 20 April 2017, and 17 July 2017]), along with expert opinion, were used to aid in the mapping of Phragmites and other nontarget species. Seven categories were identified for detection within the POC 
AOI: open water/floating and submerged aquatic vegetation, Delta Phragmites (less dense or intermixed with water), Delta Phragmites (dense), European Phragmites, shrub/woody vegetation, developed, and recently restored land.

Two distinct spectral indices, the WorldView Water Index (WV-WI) and the WorldView Improved Vegetation Index (WV-VI) were used to classify open water and floating and submerged aquatic vegetation areas in the image. The WV-WI utilizes the WV3 coastal and NIR2 spectral bands to detect areas of standing water greater than a pixel in size and is represented by the following equation (Wolf 2012):

$$
\mathrm{WV}-\mathrm{WI}=\frac{\text { Coastal }-\mathrm{NIR} 2}{\text { Coastal }+ \text { NIR2 }}
$$

WV-WI values are represented as a range from -1 to 1 , where -1 denotes areas that do not contain water and 1 signifies areas of open water. From visual inspection, open water and some floating and submerged aquatic vegetation areas were best detected when $\mathrm{WV}$-WI values were $>-0.75$.

As mentioned previously, the WV-VI equation, presented below, utilizes WorldView's NIR2 and Red bands (Wolf 2012; Tarantino et al. 2012). WVVI values are represented as a range from -1 to 1 , where -1 denotes areas of open water and 1 signifies areas that display enhanced biomass signatures. From visual inspection, most floating and submerged aquatic vegetation areas were best detected when WV-VI values were $>0.89$.

$$
\mathrm{WV}-\mathrm{VI}=\frac{\mathrm{NIR} 2-\mathrm{Red}}{\mathrm{NIR} 2+\text { Red }}
$$

When using the WV-VI method, some shrubs/woody vegetation were incorrectly classified as floating and submerged aquatic vegetation due to similar spectral signatures. To address this class confusion, regions of interest (ROI) were identified to assign woody shrubs into a separate class. The remaining pixels were included in an iterative process of unsupervised classification using the ISODATA classification algorithm and supervised classification using the Maximum Likelihood Classification algorithm and training sites (based on ancillary data). The ROIs were used to train the classifier and distinguish Phragmites haplotypes from other non-target species. Prior to classification, the spectral signatures of all training samples were compared in a pair-wise ROI separability algorithm in ENVI 5.4.1 to ensure class separation and accurate identification. 


\section{Results and Discussions}

\subsection{Moderate resolution data}

As described in the Methods section, moderate resolution imagery from Landsat- 5 TM and Landsat-8 OLI sensors, within the period of analysis (2008 and 2017), were acquired from the GEE service. Visual assessments were performed on 92 scenes to determine image quality (i.e., clouds and spatial coverage) (Figure A1, Appendix A). Any scenes (or composites) containing appreciable cloud cover or data gaps were omitted. The qualifying scenes were used to create composites, resulting in 22 data points within the period of analysis. Though it is customary to concentrate NDVI evaluations on imagery collected during the vegetation growing season (May to September), all available imagery was considered since uncertainties exist regarding secondary stressors (i.e., changes in vegetation condition during winter senescence and recovery during the next growing season). The MRD and individual assessment unit boundaries were used to calculate summary NDVI statistics for each AOI. Figures 2 and 3 provide examples of the NDVI calculations and consist of those that bracket the initial observation (summer 2016) of the Phragmites scale. The remaining 20 NDVI figures are provided in Appendix B (Figures B-1-B-20).

Figure 2. October 2015 Landsat-8-derived NDVI of vegetation within the MRD and project AOI; red areas indicate vegetation with low plant vigor while green areas indicate healthy vegetation.

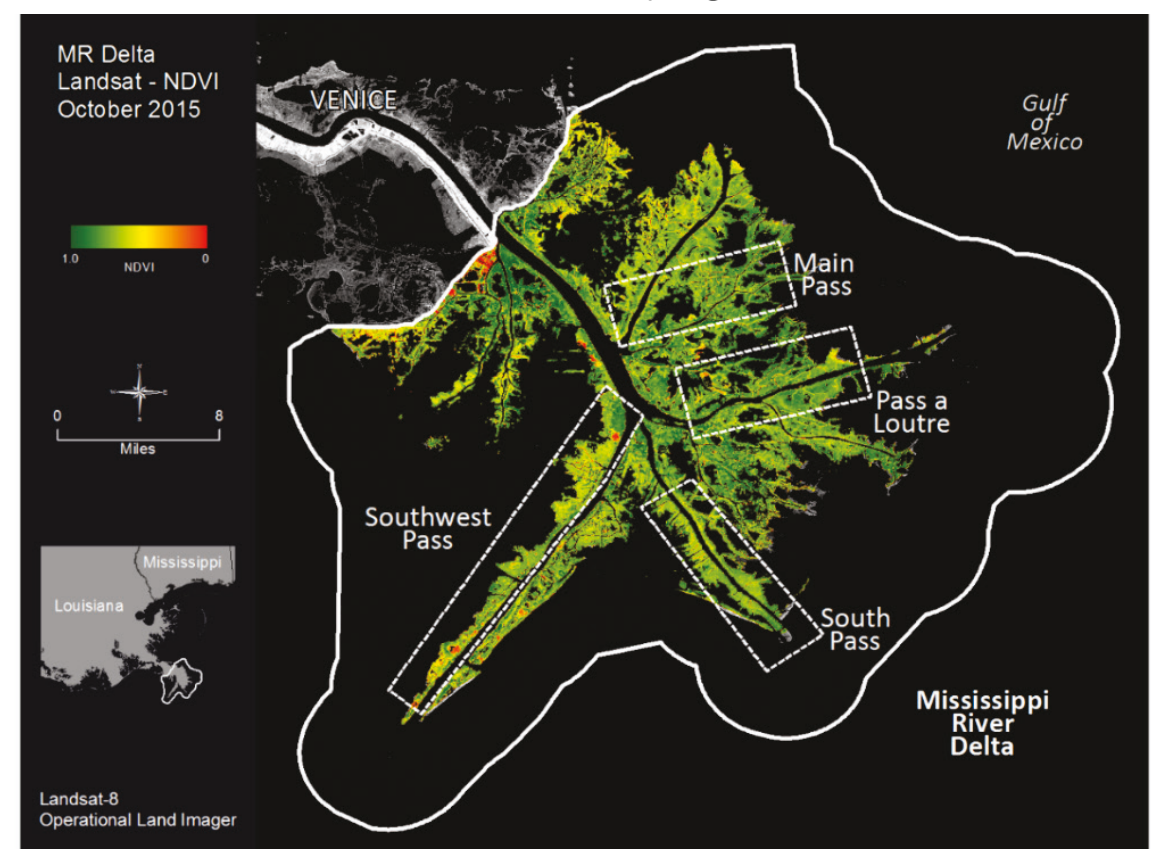


Figure 3. October 2016 Landsat-8-derived NDVI of vegetation within the MRD and project $\mathrm{AOI}$; red areas indicate vegetation with low plant vigor while green areas indicate healthy vegetation.

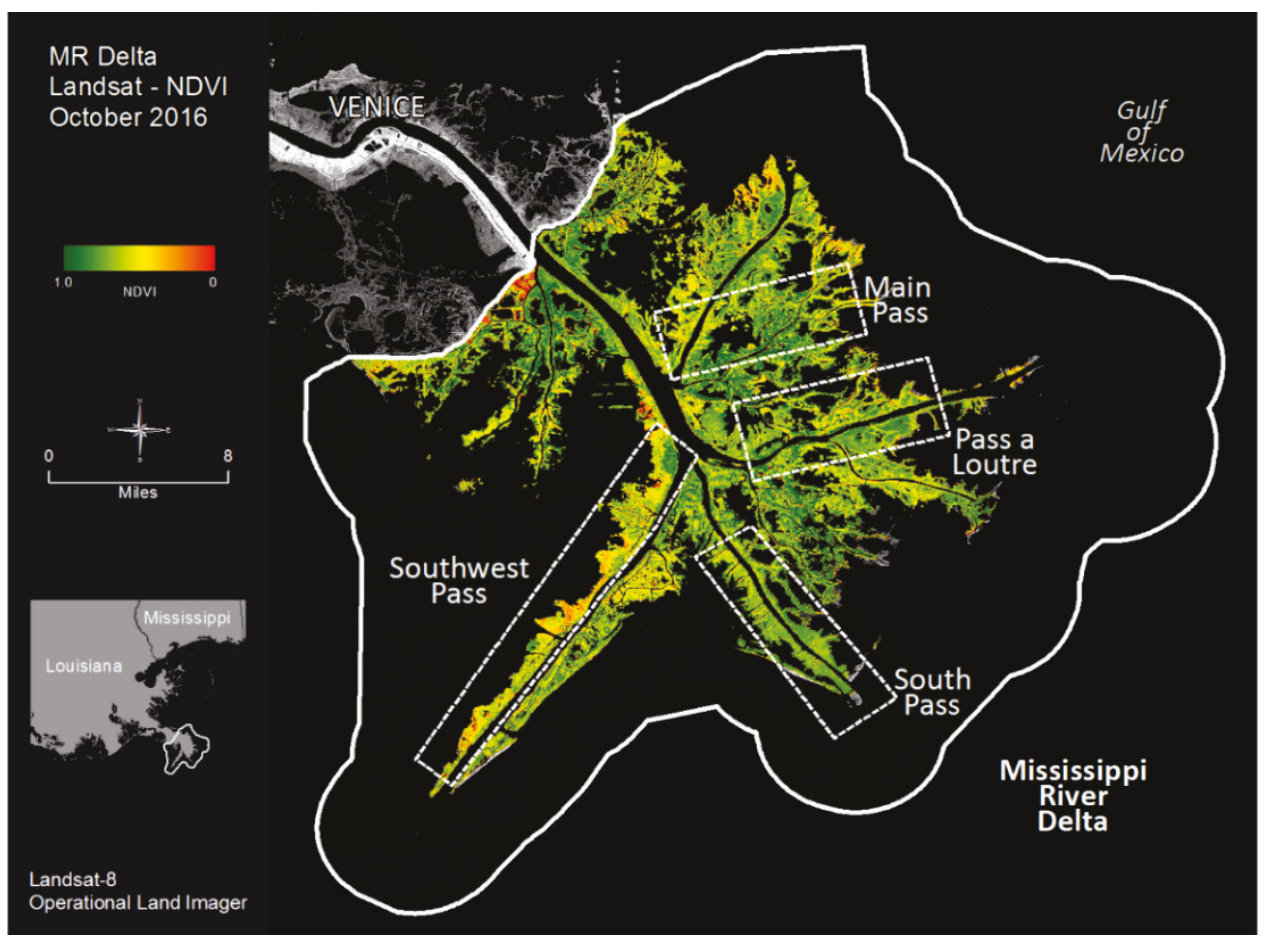

The end points from each sequential data pair (e.g., March 2008 to October 2008, October 2008 to January 2009, etc.) within the overall period of analysis were used to compute the change in NDVI for that period. Figure 4 provides an example of the NDVI changes from October 2015 to October 2016. In Figure 4, the green-blue color ramp represents increasing NDVI values, and the yellow-orange-red colors represent decreasing NDVI values. This figure shows the wetlands along the fringe of at least a portion of each major pass (waterway) experienced reductions in NDVI (productivity/health). The most severe impacts are observed along the Southwest Pass AOI, followed by Main Pass, Pass a Loutre, and South Pass. The remaining NDVI change figures are provided in Appendix B (Figures B-21-B-27).

The trajectory of mean NDVI values for each AOI through time is provided in Figure 5. These represent all qualifying data, regardless of season, and illustrate three distinct periods. The period from 2008 to 2011 where the mean NDVI values exhibited significant fluctuations due to considerable climate events (i.e., hurricanes), the period from 2011 to 2015 (pre-scale observation) where NDVI values were more stable (possible hurricane impacts observed in 2013), and the 2015 to 2017 period where the mean 
NDVI values exhibited increased fluctuation-probably injuries due to Phragmites scale (especially in Southwest Pass, which was confirmed by the preliminary field surveys). Though NDVI data provide a means of identifying periods of stress (stressors can be inferred from ancillary data), it is suspected that Phragmites recovery occurred after initial observed impacts in 2015, followed by another mean decrease in 2017. The fate of Phragmites haplotypes in relation to Phragmites scale impacts requires higher-resolution assessments. Furthermore, observed stress through NDVI calculations, while capturing Phragmites impacts, also includes impacts to other vegetation types. Thus, it is not possible to separate Phragmites impacts from other vegetation stress or injury without additional information about the location of individual species or species composition.

Figure 4. Change analysis based on Landsat-8 derived NDVI of vegetation within the MRD from October 2015 to October 2016; green-blue color ramp represents increasing NDVI values, and the yellow-orange-red colors represent decreasing NDVI values.

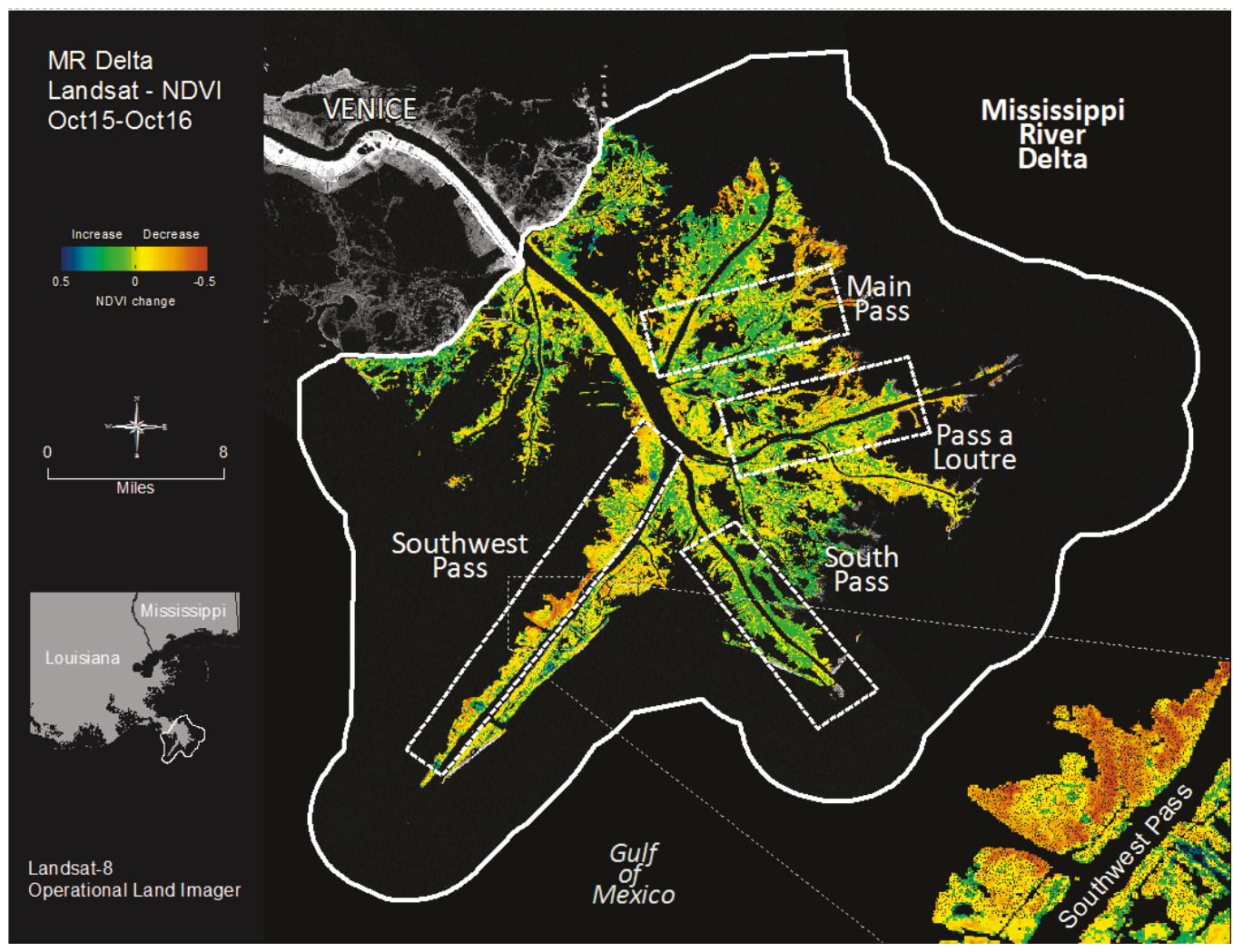


Figure 5. Graph showing mean NDVI trajectories for all Landsat-derived data points in the MRD, Main Pass, Pass a Loutre, South Pass, and Southwest Pass assessment units.

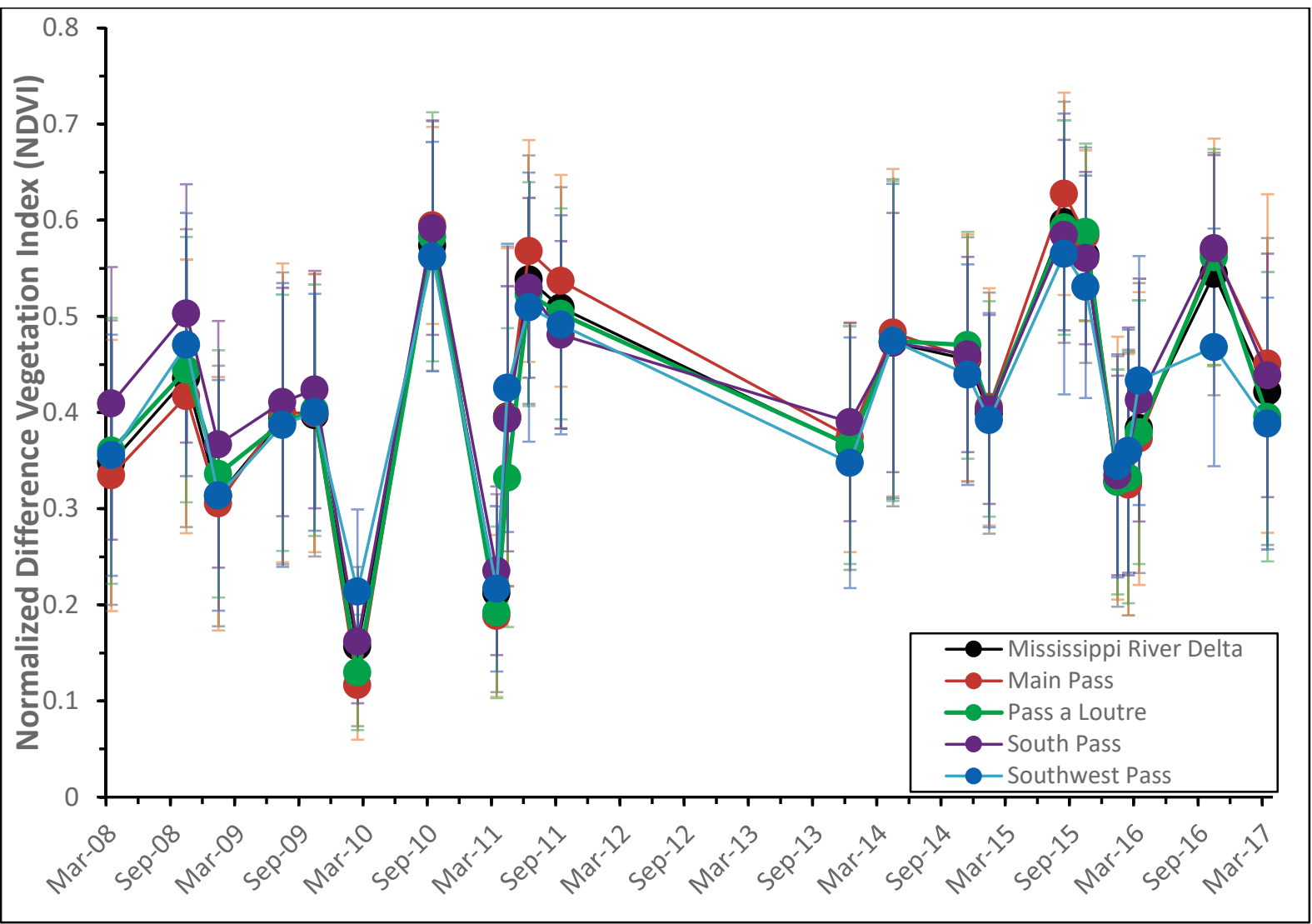

\subsection{High-resolution data}

\subsubsection{NDVI assessments}

One area of concern is within the Pass a Loutre AOI. Field surveys were used to identify areas where the robust European Phragmites haplotype (healthy, green) was adjacent to the severely impacted Delta Phragmites haplotype (stressed, brown). These impacts were potentially due to stress and injury from the Phragmites scale. Figures 6 and 7 consist of the highresolution WV-derived NDVI calculations from 2014 and 2016 and show sites where these conditions were observed. At the western end of the Pass a Loutre AOI and north of the Pass a Loutre waterway are neighboring stands of Phragmites haplotypes. Figure 6 shows that these haplotypes had high NDVI values (high productivity and health) in November of 2014. However, by October 2016 (Figure 7), large Phragmites stands were severely impacted (potentially due to Phragmites scale) and exhibited low NDVI values (orange and red - indicative of stressed vegetation). The remaining WV-derived NDVI figures are provided in Appendix C (Figures $\mathrm{C}-1$ and $\mathrm{C}-2)$. 
Figure 6. November $14 \mathrm{WV}$-derived NDVI of vegetation within the MRD and project $\mathrm{AOI}$; red areas indicate vegetation with low plant vigor while green areas indicate healthy vegetation.



Figure 7. October 2016 WV-derived NDVI of vegetation within the MRD and project AOI; red areas indicate vegetation with low plant vigor while green areas indicate healthy vegetation.

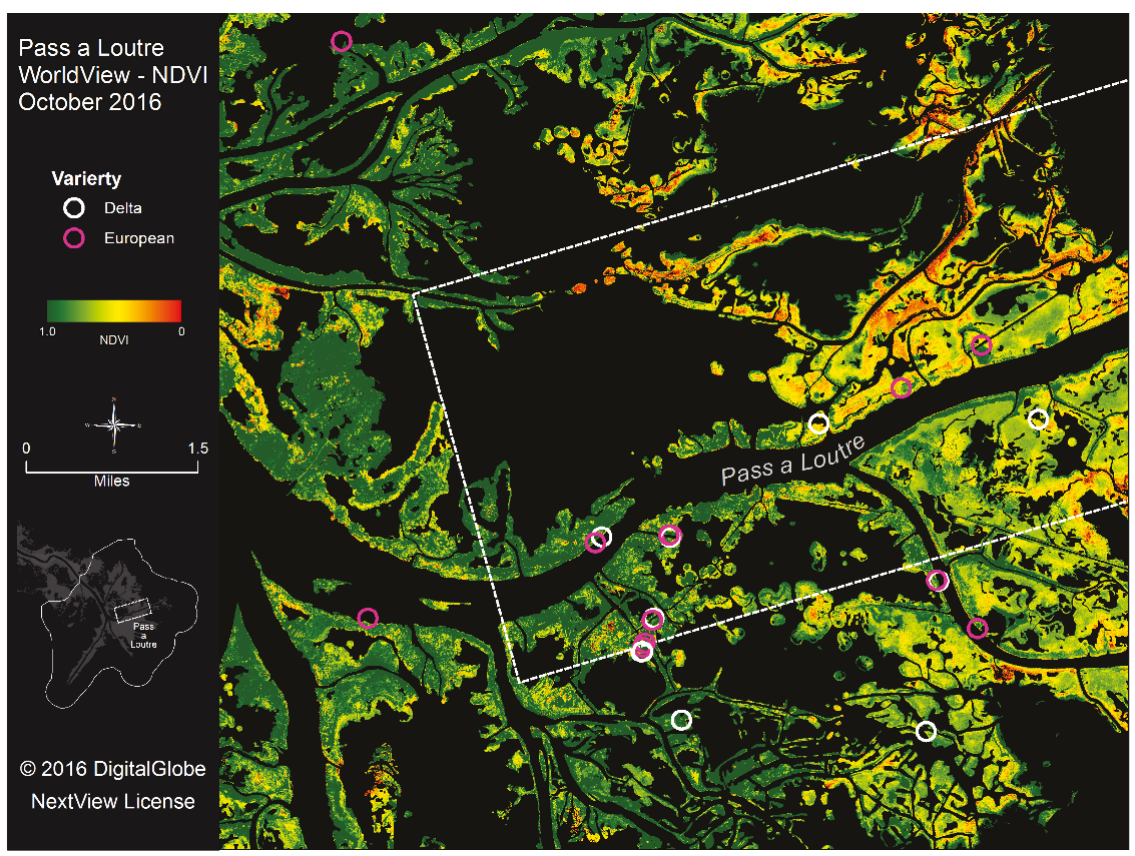

As with the Landsat NDVI calculations, change analyses were performed using the WV-derived NDVI calculations. Figure 8 illustrates the severity of NDVI change in the Pass a Loutre AOI and further highlights the utility 
of higher-resolution data for distinguishing NDVI differences in small patches of impacted and stressed vegetation. The remaining WV-derived NDVI change figures are provided in Appendix C (Figures C-3 and C-4).

Figure 8. Change analysis based on WV-derived NDVI of vegetation within the Pass a Loutre AOI from November 2014 to October 2016; green-blue color ramp represents increasing NDVI values, and the yellow-orange-red colors represent decreasing NDVI values.

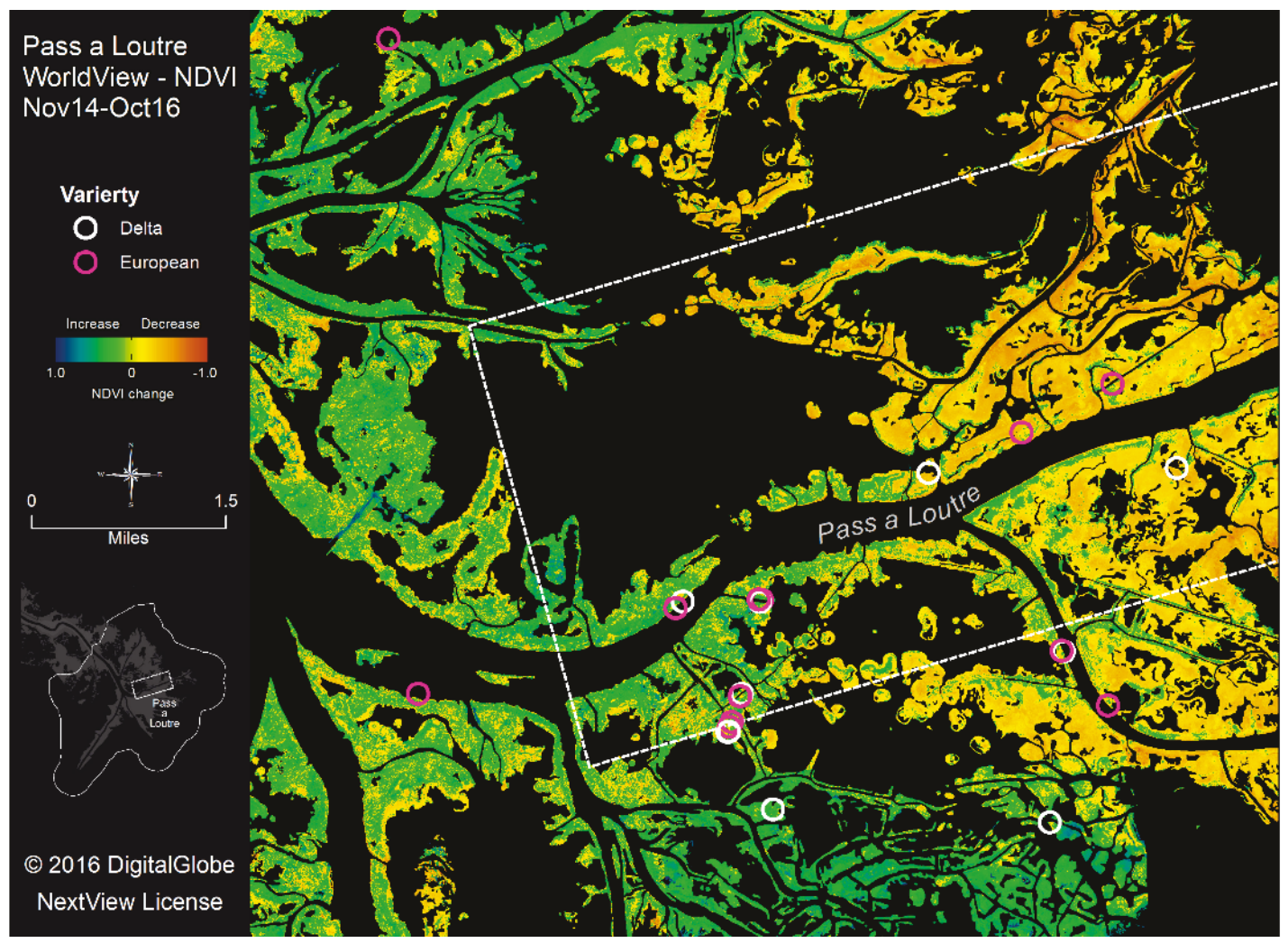

\subsubsection{Proof of Concept (POC)}

The POC classification scheme was applied to $\mathrm{WV}_{3}$ images that were collected on 1 October 2016 (Figure 9). To determine the accuracy of the image classification, 165 sample points were generated using the stratified random sampling method in ArcGIS 10.5. The method distributed the total number of sample points among each class proportional to the class area. Then, each point was verified using the ancillary ground and airborne data. Table 2 shows the number of sample points, the percentage of classification accuracy, and the percentage of total area for each class within the POC AOI. The open water/floating and submerged aquatic vegetation class accounted for $55.6 \%$ of the total area, and of the 76 sampling points identified, $85.5 \%$ were classified correctly. Most misclassified pixels were due to spectral similarities to areas consisting of water intermixed with Delta Phragmites (less dense). The Delta 
Phragmites (less dense) class comprised $13.5 \%$ of the total area of the POC AOI, and $84.2 \%$ classification accuracy was noted for the 19 sample points. The majority of errors were due to the close proximity of the class edge to floating aquatic and other plant species. The Delta Phragmites (dense) represented $21.8 \%$ of the total area of the POC AOI. A total of 30 sample points resulted in an $80 \%$ classification accuracy with most errors due to class confusion with floating aquatic plants. The European Phragmites represents $0.1 \%$ of the total area of the POC AOI with a $50 \%$ classification accuracy across 10 sample points. Differentiating between the European and Delta Phragmites haplotypes was difficult through spectral identification alone; however, field verification was useful for manually identifying European Phragmites patches. Improved species detection via WV imagery could be achieved using multi-seasonal and temporal classification to exploit differences in genotypic characteristics. The shrub/woody vegetation, developed, and recently restored land classes represent $0.9 \%, 0.1 \%$, and $8.0 \%$ of the total POC AOI area, respectively, with 10 sample points per class. The sample points of each class were verified with $100 \%$ accuracy.

Overall, the classification methods performed for this study were effective for detecting Phragmites from non-Phragmites within the POC AOI. This allows for targeted evaluation of Phragmites community trends, such as changes in plant health and stress fluctuations using NDVI analyses and other spectral indices. In addition, two separate density metrics, less dense and dense, of the European Phragmites were identified through classification. Density metrics are important indicators of vegetation quality and could be useful for monitoring impacts to vegetation through time. Phragmites species level identification proved more difficult and could benefit from the collection and analysis of hyperspectral imagery to isolate spectral signatures. Also, improved classification methods could be achieved by incorporating object-based feature extract methods based on textural, spectral, and spatial characteristics. 
Figure 9. WV3 satellite image (color infrared composite) of the POC area (top image) acquired on 1 October 2016 and the derived classification image (bottom image).




Table 2. Classification accuracy assessment listing the total number of assessment sample points per class, the accuracy percentage of the classification per class, and the percentage of total POC AOI area for each class.

\begin{tabular}{|l|c|c|c|}
\hline Class & Samples & Accuracy \% & $\%$ of Total Area \\
\hline $\begin{array}{l}\text { Open Water/Floating and Submerged } \\
\text { Aquatics }\end{array}$ & 76 & $85.5 \%$ & $55.6 \%$ \\
\hline Delta Phragmites (less dense) & 19 & $84.2 \%$ & $13.5 \%$ \\
\hline Delta Phragmites (dense) & 30 & $80.0 \%$ & $21.8 \%$ \\
\hline European Phragmites & 10 & $50.0 \%$ & $0.1 \%$ \\
\hline Shrub/Woody Vegetation & 10 & $100.0 \%$ & $0.9 \%$ \\
\hline Developed & 10 & $100.0 \%$ & $0.1 \%$ \\
\hline Recently Restored Land & 10 & $100.0 \%$ & $8.0 \%$ \\
\hline
\end{tabular}




\section{Conclusions}

In summary, the short-term efforts from this study yielded preliminary remote sensing methods to assess vegetation in scale-impacted areas of the MRD. The products were developed in coordination with the U.S. Geological Survey, which likewise investigated the use of NDVI to map recent, relative biomass changes from 2014 to 2017 (Ramsey and Rangoonwala 2017). As a result of coordinated efforts and findings, as well as discussions with LSU and the USACE New Orleans District, it was determined that historical changes in NDVI prior to 2014 as well as methods to discriminate Phragmites from non-target species are necessary to better understand vegetation impacts, especially in cases where Phragmites haplotypes experience different impacts and where new species are colonizing impacted Phragmites habitat. While NDVI trend analyses are a valuable data source, providing a rapid and cursory understanding of vegetation health, they are limited in that they do not explain which particular species are stressed or injured. Thus, the POC illustrates how field data can be utilized with high-resolution satellite imagery to identify species of interest in the MRD.

The methods described in this report are useful for evaluating scale impacts in areas where vegetation provides important benefits (i.e., protection from erosion). Rapid decline of Phragmites and recolonization by other plant species has unclear implications for surrounding ecosystem integrity, navigation, and flood protection. With regard to navigation, there are five federal navigation channels and four ports in the impacted area. Southwest Pass, for example, is a primary shipping channel in the United States and could face increased wave action if the Phragmites marsh lining the channel should collapse. Other potential negative effects could include increased flooding, erosion, and storm-related damage. The data provide operational value for future assessments of vegetation and wetland loss on navigation (dredging) and flood risks. In addition, they are useful for prioritizing future data collections and analysis efforts in nearby studies, such as the Louisiana Coastal Area Beneficial Use of Dredge Material West Bay and Tiger Pass Projects.

Future work should continue with the development of NDVI calculations and map products using collections of Landsat and WV imagery to track and monitor potential Phragmites die-off areas as expressed through relative biomass changes. Future work should also expand upon 
preliminary species-based classification testing and development conducted at Pass a Loutre to other AOI utilizing high-resolution remotely sensed data where rapid decline in Phragmites has resulted in new species establishment. Additionally, to better quantify and understand haplotype and species impacts as well as tolerance to environmental stress, direct linkages between Phragmites die-off areas and species classifications are necessary. Comparison of species composition information coupled with change in plant biomass would (1) improve summary statistics for impacted and changing vegetation types since species impacts are not uniform; (2) improve the understanding of the Phragmites haplotype impacts on a regional perspective; and (3) provide an approach to monitor non-target species that are likewise changing in response to declining Phragmites-dominated habitats. Future work should also integrate biomass and species level data with landscape metrics (i.e., connectivity, interspersion, edge density, and core area), vegetation quality indices, and suitability/susceptibility models to evaluate hotspots and ecosystem integrity to support pest and resource management. 


\section{References}

Achenbach, L., and H. Brix. 2014. "Can Differences in Salinity Tolerance Explain the Distribution of Four Genetically Distinct Lineages of Phragmites australis in the Mississippi River Delta?” Hydrobiologia 737(1): 5-23.

Allen, Y. C., and G. M. Suir. 2014. Using High-Resolution, Regional-Scale Data to Characterize Floating Aquatic Nuisance Vegetation in Coastal Louisiana Navigation Channels. ERDC/TN-APCRP-EA-27. Vicksburg, MS: U.S. Army Research and Development Center.

An, N., K. P. Price, and J. M. Blair. 2013. "Estimating Above-Ground Net Primary Productivity of the Tallgrass Prairie Ecosystem of the Central Great Plains Using AVHRR NDVI.” International Journal of Remote Sensing 34(11): 3,717-3,735.

Bianchette, T. A., K. B. Liu, N. S. N. Lam, and L. M. Kiage. 2009. "Ecological Impacts of Hurricane Ivan on the Gulf Coast of Alabama: A Remote Sensing Study. Journal of Coastal Research, Special Issue No. 56." In Proceedings of the $10^{\text {th }}$ International Coastal Symposium ICS 2009 2: 1,622-1,626.

Burdick, D. M., and R. A. Konisky. 2003. "Determinants of Expansion for Phragmites australis, Common Reed, in Natural and Impacted Coastal Marshes." Estuaries and Coasts 26(2): 407-416.

Cardoch, L., J. W. Day, and C. Ibàñez. 2002. "Net Primary Productivity as an Indicator of Sustainability in the Ebro and Mississippi Deltas.” Ecological Applications 12(4): $1,044-1,055$.

Carle, M. 2013. Spatial Structure and Dynamics of the Plant Communities in a ProGrading River Delta: Wax Lake Delta, Atchafalaya Bay, Louisiana. PhD dissertation. Baton Rouge, LA: Louisiana State University.

Chabreck, R. H., and A. W. Palmisano. 1973. "The Effects of Hurricane Camille on the Marshes of the Mississippi River Delta." Ecology 54(5): 1,118-1,123.

Chander, G., B. L. Markham, and D. L. Helder. 2009. "Summary of Current Radiometric Calibration Coefficients for Landsat MSS, TM, ETM+, and EO-1 ALI Sensors.” Remote Sensing of Environment 113(5): 893-903.

Coleman, J. M., H. H. Roberts, and G. W. Stone. 1998. "Mississippi River Delta: An Overview.” Journal of Coastal Research 14(3): 699-716.

Couvillion, B. R., J. A. Barras, G. D. Steyer, W. Sleavin, M. Fischer, H. Beck, N. Trahan, B. Griffin, and D. Heckman. 2011. Land Area Change in Coastal Louisiana from 1932 to 2010: Scientific Investigations Map 3164. Reston, VA: U.S. Geological Survey.

Couvillion, B. R., and H. Beck. 2013. "Marsh Collapse Thresholds for Coastal Louisiana Estimated Using Elevation and Vegetation Index Data." Journal of Coastal Research 63(1): 58-67. 
Day, J. W., L. D. Britsch, S. R. Hawes, G. P. Shaffer, D. J. Reed, and D. Cahoon. 2000. "Pattern and Process of Land Loss in the Mississippi Delta: A Spatial and Temporal Analysis of Wetland Habitat Change." Estuaries and Coasts 23(4): 425-438.

Diaz, R., J. T. Cronin, B. Wilson, and J. A. Nyman. 2017. Development of a Management Program for Roseau Cane Die-Offs. LSU Agricultural Center, Baton Rouge, LA. http://edit.Isuagcenter.com/ /media/system/c/f/b/0/cfb0042dc92b3e319db344642d2705 75/development\%20of\%20a\%20management\%20program\%20for\%20roseau\%20cane\%20diefor\%20websitedocx.docx

Hauber, D. P., K. Saltonstall, D. A. White, and C. S. Hood. 2011. "Genetic Variation in the Common Reed, Phragmites australis, in the Mississippi River Delta Marshes: Evidence for Multiple Introductions." Estuaries and Coasts 34(4): 851-862.

Howard, R. J., S. E. Travis, and B. A. Sikes. 2008. "Rapid Growth of a Eurasian Haplotype of Phragmites australis in a Restored Brackish Marsh in Louisiana, USA.” Biological Invasions 10(3): 369-379.

Kaneko, S. 2004. "Within-Plant Vertical Distributions of the Scale Insect Nipponaclerda biwakoensis and Its Five Parasitoids That Exhibit Frequent Successful Multiparasitism on the Common Reed." Entomological Science 7(4): 331-339.

Klemas, V. 2013. "Using Remote Sensing to Select and Monitor Wetland Restoration Sites: An Overview.” Journal of Coastal Research 29(4): 958-970.

Lambertini, C., I. A. Mendelssohn, M. H. G. Gustafsson, B. Olesen, T. Riis, B. K. Sorrell, and H. Brix. 2012. "Tracing the Origin of Gulf Coast Phragmites (Poaceae): A Story of Long-Distance Dispersal and Hybridization.” American Journal of Botany 99: 538-551.

Lane, C. R., O. Anenkhonov, H. Liu, B. Autrey, and V. Chepinoga. 2015. "Classification and Inventory of Freshwater Wetlands and Aquatic Habitats in the Selenga River Delta of Lake Baikal Russia, Using High-Resolution Satellite Imagery." Wetlands Ecology and Management 23: 195. https://doi.org/10.1007/s11273-014-9369-z

McCarthy, M., E. Merton, and F. Muller-Karger. 2015. "Improved Coastal Wetland Mapping Using Very- High 2-Meter Spatial Resolution Imagery.” International Journal of Applied Earth Observation and Geoinformation 40: 11-18.

McConnell, H. S. 1954. A Classification of the Coccid Family Aclerdidae (Coccoidea, Homoptera). Bulletin of the Maryland Agriculture Experiment Station A75: 1121.

Meyerson, L. A., A. M. Lambert, and K. Saltonstall. 2010. "A Tale of Three Lineages: Expansion of Common Reed (Phragmites australis) in the U.S. Southwest and Gulf Coast.” Invasive Plant Science and Management 3(4): 515-520.

Ramsey, E. W., III, and A. Rangoonwala. 2017. Mapping the Change of Phragmites australis Live Biomass in the Lower Mississippi River Delta Marshes. U.S. Geological Survey Open-File Report 2017-1098.

https://doi.org/10.3133/ofr20171098 
Rapinel, S., B. Clement, S. Magnanon, V. Sellin, and L. Hubert-Moy. 2014. "Identification and Mapping of Natural Vegetation on a Coastal Site Using a Worldview-2 Satellite Image.” Journal of Environmental Management 144: 236-246.

Reif, M. K., C. L. Macon, and J. M. Wozencraft. 2011. "Post-Katrina Land-Cover, Elevation, and Volume Change Assessment along the South Shore of Lake Pontchartrain, Louisiana, U.S.A.” Journal of Coastal Research Special Issue No. 62: $30-39$.

Rouse, J. W., R. H. Haas, J. A. Schell, and D. W. Deering. 1974. Monitoring Vegetation Systems in the Great Plains with ERTS. Paper presented at the Proceedings, Third Earth Resources Technology Satellite-1 Symposium. Washington, DC: Goddard Space Flight Center.

Saltonstall, K. 2002. "Cryptic Invasion of a Non-Native Haplotype of the Common Reed, Phragmites australis, into North America." Proc. Natl. Acad. Sci. USA 99: 2,4452,449 .

Steyer, G. D., B. R. Couvillion, and J. A. Barras. 2013. "Monitoring Vegetation Response to Episodic Disturbance Events by Using Multitemporal Vegetation Indices.” Journal of Coastal Research 63(sp1): 118-130.

Strahler, A. H., W. Lucht, C. B. Schaaf, T. Tsang, F. Gao, X. Li, J. P. Muller, P. Lewis, and M. J. Barnsley. 1999. MODIS BRDF/Albedo Product: Algorithm Theoretical Basis Document Version 5.o. MODIS Product Document ID: MOD43. https://modis.gsfc.nasa.gov/data/atbd/atbd_mod09.pdf

Suir, G. M., W. R., Jones, A. L. Garber, and J. A. Barras. 2014. Pictorial Account and Landscape Evolution of the Crevasses near Fort St. Philip, Louisiana (No. 2). U.S. Army Corps of Engineers. https://pubs.er.usgs.gov/publication/70094484

Suir, G. M., C. L. Saltus, and J. A. Barras. 2011. Development of Methodology to Classify Historical Aerial Photography to Analyze Land Area and Shoreline Change in Coastal Louisiana - Point Au Fer Island - from 1956-2009; A Case Study. ERDC/EL TR-11-17. Vicksburg, MS: U.S. Army Engineer Research and Development Center.

Suir, G. M., M. Reif, S. Hammond, S. Jackson, and K. Brodie. 2018. Unmanned Aircraft Systems to Support Environmental Applications within USACE Civil Works. ERDC SR-18-3. Vicksburg, MS: U.S. Army Engineer Research and Development Center. https://erdc library.erdc.dren.mil/xmlui/handle/11681/27428

Tarantino C., M. Adamo, G. Pasquariello, F. Lovergine, P. Blonda, and V. Tomaselli. 2012. 8-Band Image Data Processing of the Worldview-2 Satellite in a Wide Area of Applications. Earth Observation. Edited by Dr. Rustam Rustamov. ISBN: 978953-307-973-8, InTech. https://www.intechopen.com/books/earth-observation/8-bandimage-data-processing-of-the-worldview-2-satellite-in-a-wide-area-of-applications

Wolf, A. F. 2012. "Using WorldView-2 Vis-NIR Multispectral Imagery to Support Land Mapping and Feature Extraction Using Normalized Difference Index Ratios." In Algorithms and Technologies for Multispectral, Hyperspectral, and Ultraspectral Imagery XVIII (Vol. 8390, p. 83900N). International Society for Optics and Photonics. 


\section{Appendix A: Imagery Catalog}

Table A-1. Catalog of moderate (white cells) and high resolution (grey cells) imagery for the MRD, Southwest Pass (SW), South Pass (S), Pass a Loutre (Loutre), and Main Pass (Main) assessment units.

\begin{tabular}{|c|c|c|c|c|c|c|c|c|}
\hline Satellite & $\begin{array}{c}\text { Collection } \\
\text { Date }\end{array}$ & $\begin{array}{c}\text { Scene / } \\
\text { AOI }\end{array}$ & Satellite & $\begin{array}{c}\text { Collection } \\
\text { Date }\end{array}$ & $\begin{array}{c}\text { Scene / } \\
\text { AOI }\end{array}$ & Satellite & $\begin{array}{c}\text { Collection } \\
\text { Date }\end{array}$ & Scene / AOI \\
\hline Landsat-8 & 30-Mar-17 & Barataria & Landsat-5 & 30-Sep-11 & MRD & Landsat-5 & 21-Mar-08 & Barataria \\
\hline Landsat-8 & 6-Mar-17 & MRD & Landsat-5 & 6-Sep-11 & Barataria & Landsat-5 & 13-Mar-08 & MRD \\
\hline Landsat-8 & 16-Nov-16 & MRD & Landsat-5 & 13-Aug-11 & MRD & Landsat-5 & 2-Feb-08 & Barataria \\
\hline Landsat-8 & $31-O c t-16$ & MRD & Landsat-5 & 10-Jun-11 & MRD & Worldview 3 & 20-Jul-17 & Main and Loutre \\
\hline Landsat-8 & 7-Oct-16 & Barataria & Landsat-5 & 2-Jun-11 & Barataria & Worldview 3 & 1-Oct-16 & SW, S, Loutre, Main \\
\hline Landsat-8 & 22-Apr-16 & MRD & Landsat-5 & 15-Apr-11 & Barataria & Worldview 3 & 3-Apr-16 & SW. S. Main \\
\hline Landsat-8 & 21-Mar-16 & MRD & Landsat-5 & 7-Apr-11 & MRD & Worldview 3 & 13-Aug-15 & SW \\
\hline Landsat-8 & 13-Mar-16 & Barataria & Landsat-5 & 30-Mar-11 & Barataria & Worldview 3 & 8-Apr-15 & SW \\
\hline Landsat-8 & 5-Mar-16 & MRD & Landsat-5 & 14-Mar-11 & Barataria & Worldview 3 & 8-Mar-15 & SW. S. Loutre. Main \\
\hline Landsat-8 & 26-Feb-16 & Barataria & Landsat-5 & 18-Feb-11 & MRD & Worldview 3 & 14-Nov-14 & SW, S, Loutre, Main \\
\hline Landsat-8 & 18-Feb-16 & MRD & Landsat-5 & $10-$ Feb-11 & Barataria & Worldview 3 & $26-O c t-14$ & SW, Main \\
\hline Landsat-8 & $10-F e b-16$ & Barataria & Landsat-5 & 19-Dec-10 & MRD & Worldview 2 & 20-Apr-17 & S, Loutre, Main \\
\hline Landsat-8 & 17-Jan-16 & MRD & Landsat-5 & 1-Nov-10 & MRD & Worldview 2 & $12-A p r-17$ & Main, Loutre \\
\hline Landsat-8 & 17-Nov-15 & Barataria & Landsat-5 & 16-Oct-10 & MRD & Worldview 2 & 15-Jun-15 & SW \\
\hline Landsat-8 & 8-Oct-15 & MRD & Landsat-5 & 30-Sep-10 & MRD & Worldview 2 & 10-Nov-14 & SW \\
\hline Landsat-8 & 14-Sep-15 & Barataria & Landsat-5 & 22-Mar-10 & Barataria & Worldview 2 & 17-Jun-14 & Main, Loutre \\
\hline Landsat-8 & 21-Aug-15 & MRD & Landsat-5 & $18-F e b-10$ & MRD & Worldview 2 & 16-Jan-14 & SW. S. Loutre. Main \\
\hline Landsat-8 & 20-Jul-15 & MRD & Landsat-5 & 2-Feb-10 & MRD & Worldview 2 & 3-Nov-13 & SW, S, Loutre, Main \\
\hline Landsat-8 & 22-Mar-15 & Barataria & Landsat-5 & 9-Nov-09 & MRD & Worldview 2 & 7-Nov-12 & SW \\
\hline Landsat- 8 & 2-Feb-15 & Barataria & Landsat-5 & 1-Nov-09 & Barataria & Worldview 2 & $11-$ Oct-12 & SW, S, Loutre, Main \\
\hline Landsat-8 & 25-Jan-15 & MRD & Landsat-5 & 24-Oct-09 & MRD & Worldview 2 & 6-Oct-12 & SW, S, Loutre, Main \\
\hline Landsat-8 & 1-Jan-15 & Barataria & Landsat-5 & 16-Oct-09 & Barataria & Worldview 2 & 5-Oct-11 & SW \\
\hline Landsat-8 & 11-Dec-14 & MRD & Landsat-5 & 29-Aug-09 & Barataria & Worldview 2 & 28-Aug-11 & S, Main, Loutre \\
\hline Landsat- 8 & 25-Nov-14 & MRD & Landsat-5 & 18-Jun-09 & MRD & Worldview 2 & 1-Aug-10 & Main, Loutre \\
\hline Landsat-8 & 17-Nov-14 & Barataria & Landsat-5 & 2-Jun-09 & MRD & GeoEYE & 18-Nov-12 & SW \\
\hline Landsat-8 & 1-Nov-14 & Barataria & Landsat-5 & 15-Apr-09 & MRD & GeoEYE & 2-Oct-12 & SW, S, Loutre, Main \\
\hline Landsat-8 & 28-Jul-14 & Barataria & Landsat-5 & 2-Feb-09 & Barataria & GeoEYE & 3-Mar-10 & SW, S, Loutre, Main \\
\hline Landsat-8 & 17-May-14 & MRD & Landsat-5 & 25-Jan-09 & MRD & GeoEYE & $17-F e b-10$ & SW and S \\
\hline Landsat-8 & 1-Mav-14 & MRD & Landsat-5 & 17-Jan-09 & Barataria & QuickBird 2 & 24-Oct-14 & SW, S, Loutre, Main \\
\hline Landsat-8 & 7-Apr-14 & Barataria & Landsat-5 & 9-Jan-09 & MRD & QuickBird 2 & 23-Apr-14 & SW \\
\hline Landsat-8 & 17-Jan-14 & Barataria & Landsat-5 & 16-Nov-08 & Barataria & QuickBird 2 & $23-O c t-10$ & S, Loutre, Main \\
\hline Landsat-8 & 9-Jan-14 & MRD & Landsat-5 & 31-Oct-08 & Barataria & QuickBird 2 & 24-Mav-10 & Loutre \\
\hline Landsat-8 & 11-Dec-13 & MRD & Landsat-5 & 23-Oct-08 & MRD & QuickBird 2 & 15-Mar-06 & SW and Main \\
\hline Landsat-8 & $24-O c t-13$ & MRD & Landsat-5 & 29-Sep-08 & Barataria & QuickBird 2 & 11-Sep-05 & SW \\
\hline Landsat-5 & 9-Nov-11 & Barataria & Landsat-5 & 28-Aug-08 & Barataria & - & - & - \\
\hline Landsat-5 & 16-Oct-11 & MRD & Landsat-5 & 16-Mav-08 & MRD & - & - & - \\
\hline
\end{tabular}




\section{Appendix B: Landsat-Derived NDVI}

Figure B-1. March 2008 Landsat-8-derived NDVI of vegetation within the Mississippi River Delta and project AOI.

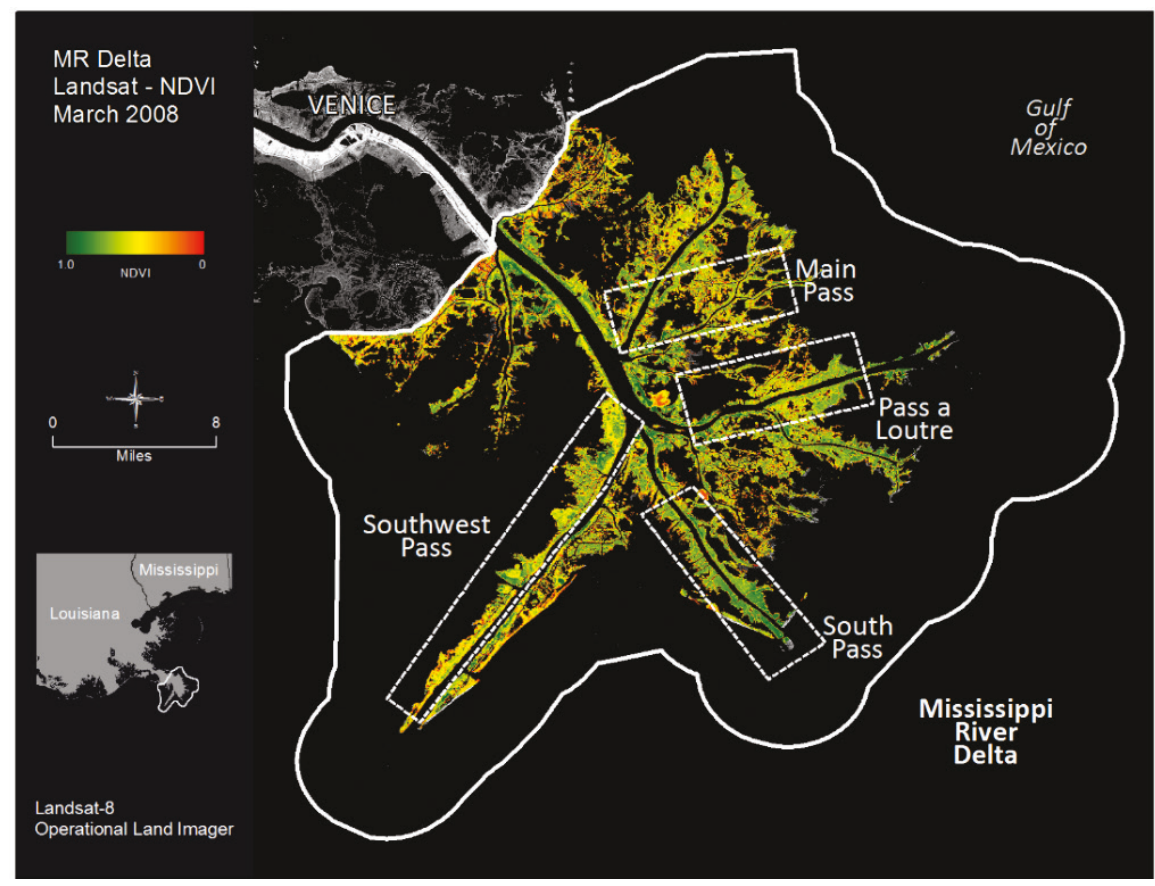

Figure B-2. October 2008 Landsat-8-derived NDVI of vegetation within the Mississippi River Delta and project AOI.

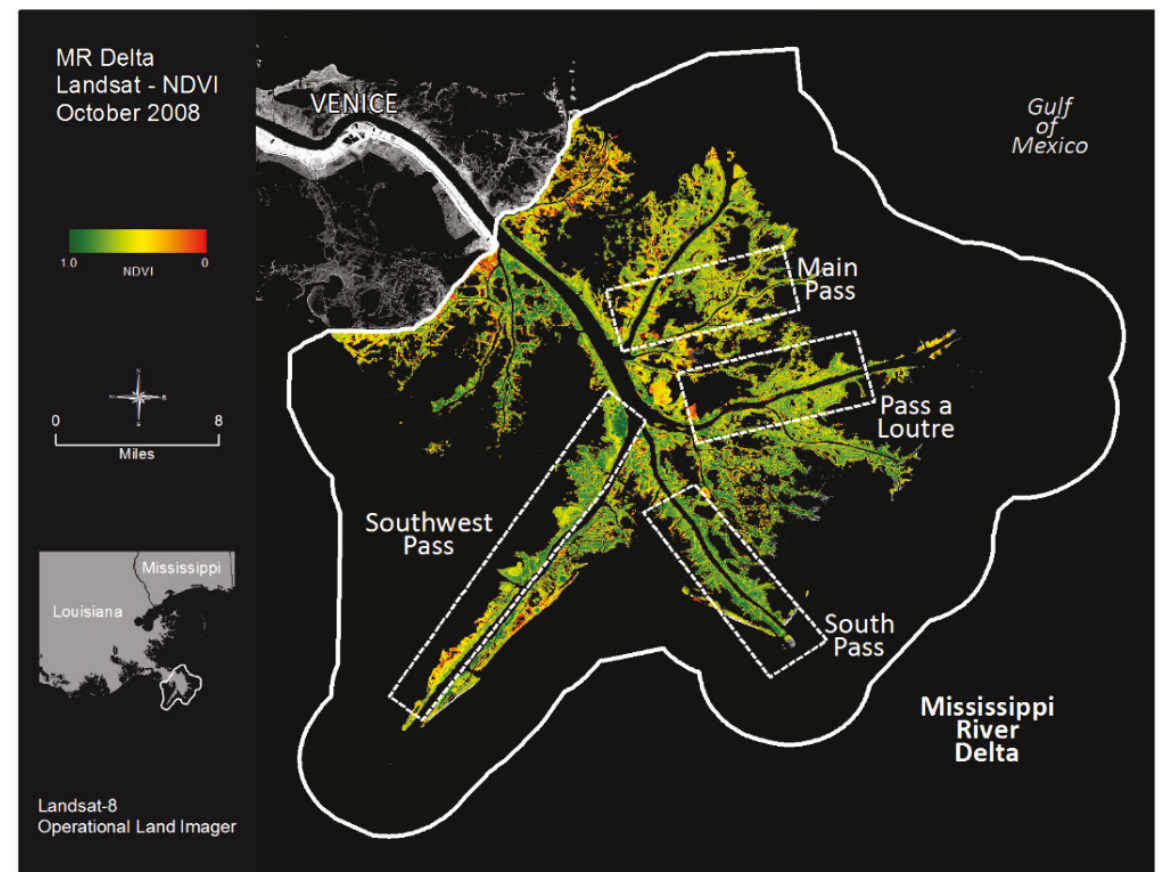


Figure B-3. January 2009 Landsat-8-derived NDVI of vegetation within the Mississippi River Delta and project AOI.

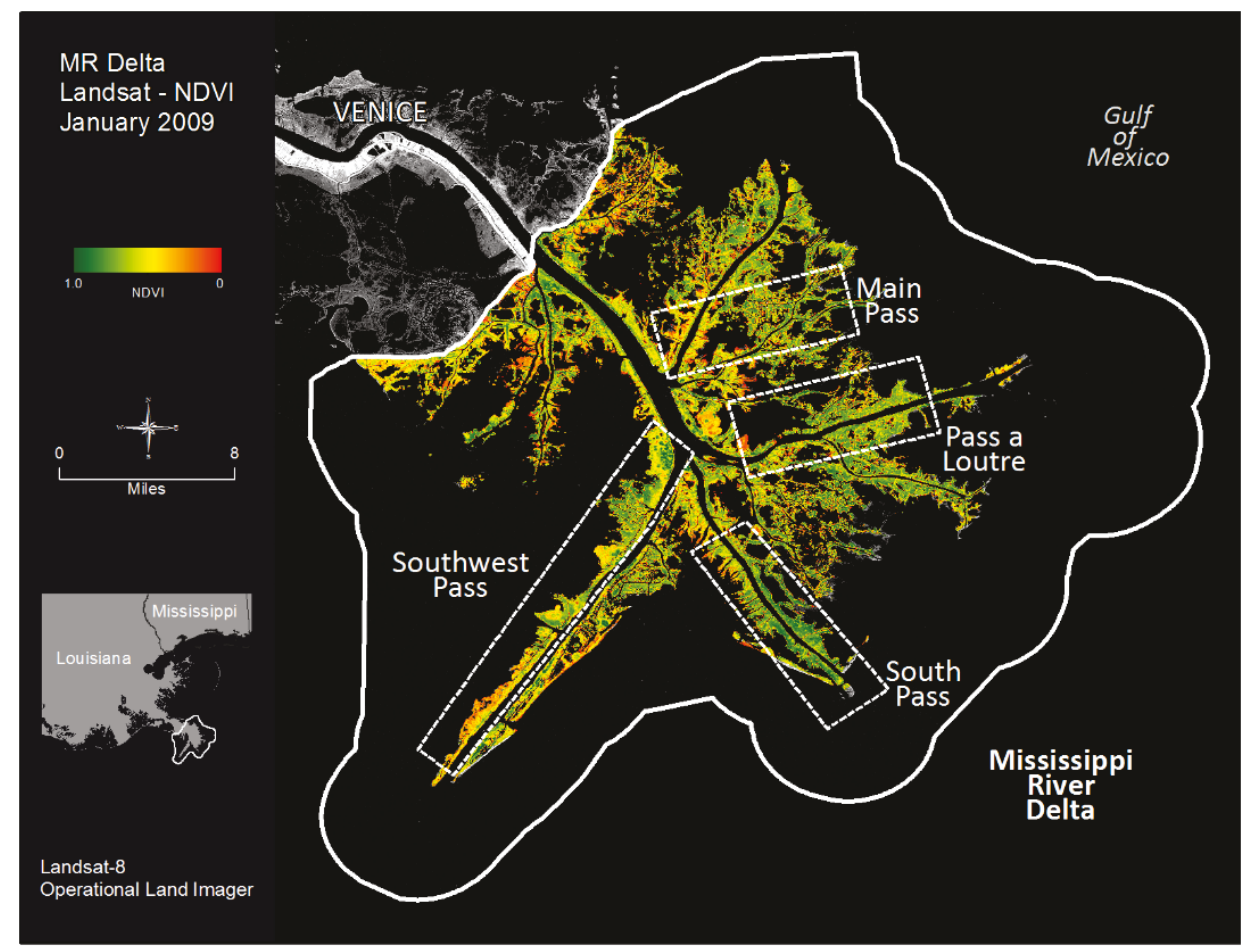

Figure B-4. July 2009 Landsat-8-derived NDVI of vegetation within the Mississippi River Delta and project AOI.

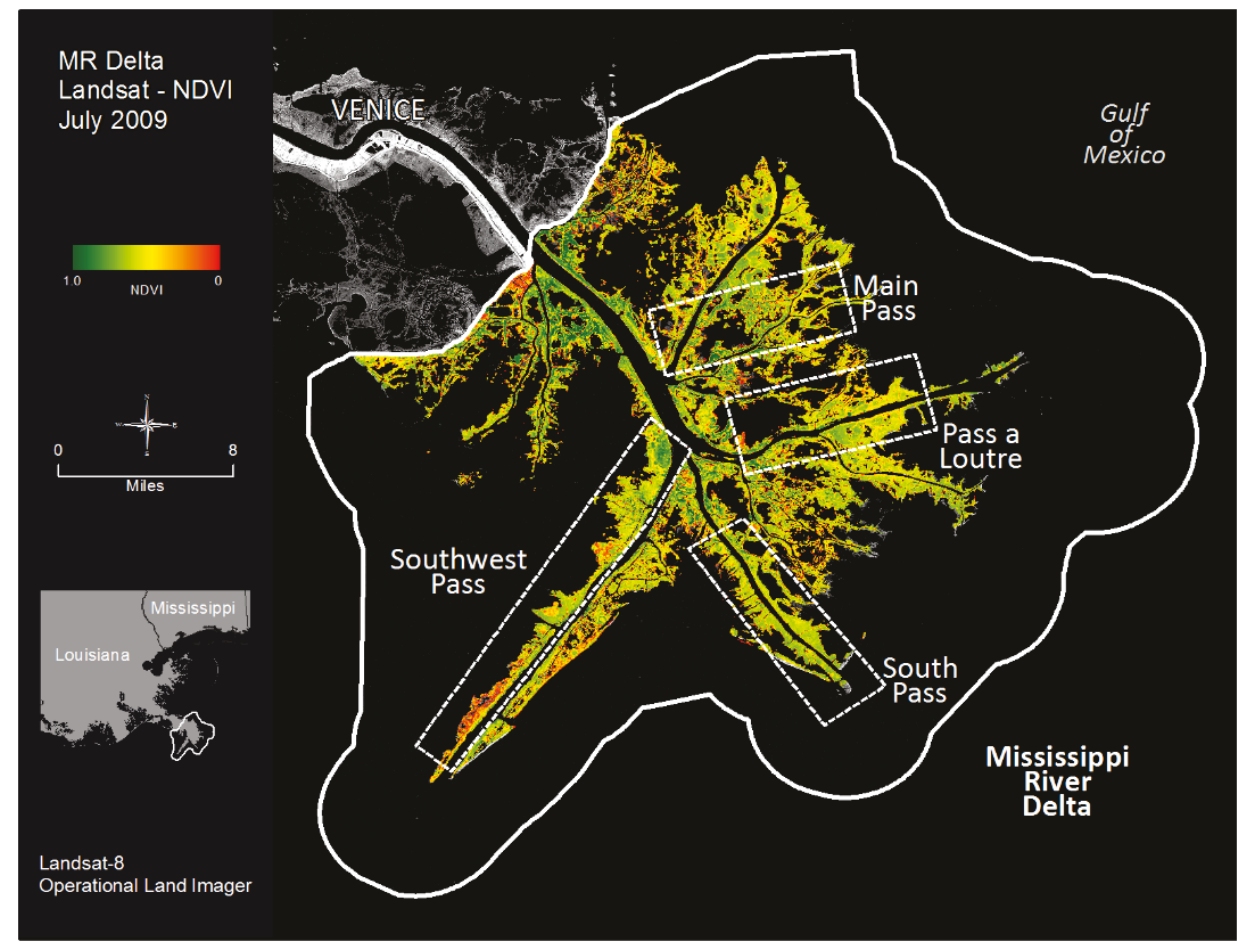


Figure B-5. October 2009 Landsat-8-derived NDVI of vegetation within the Mississippi River Delta and project AOI.

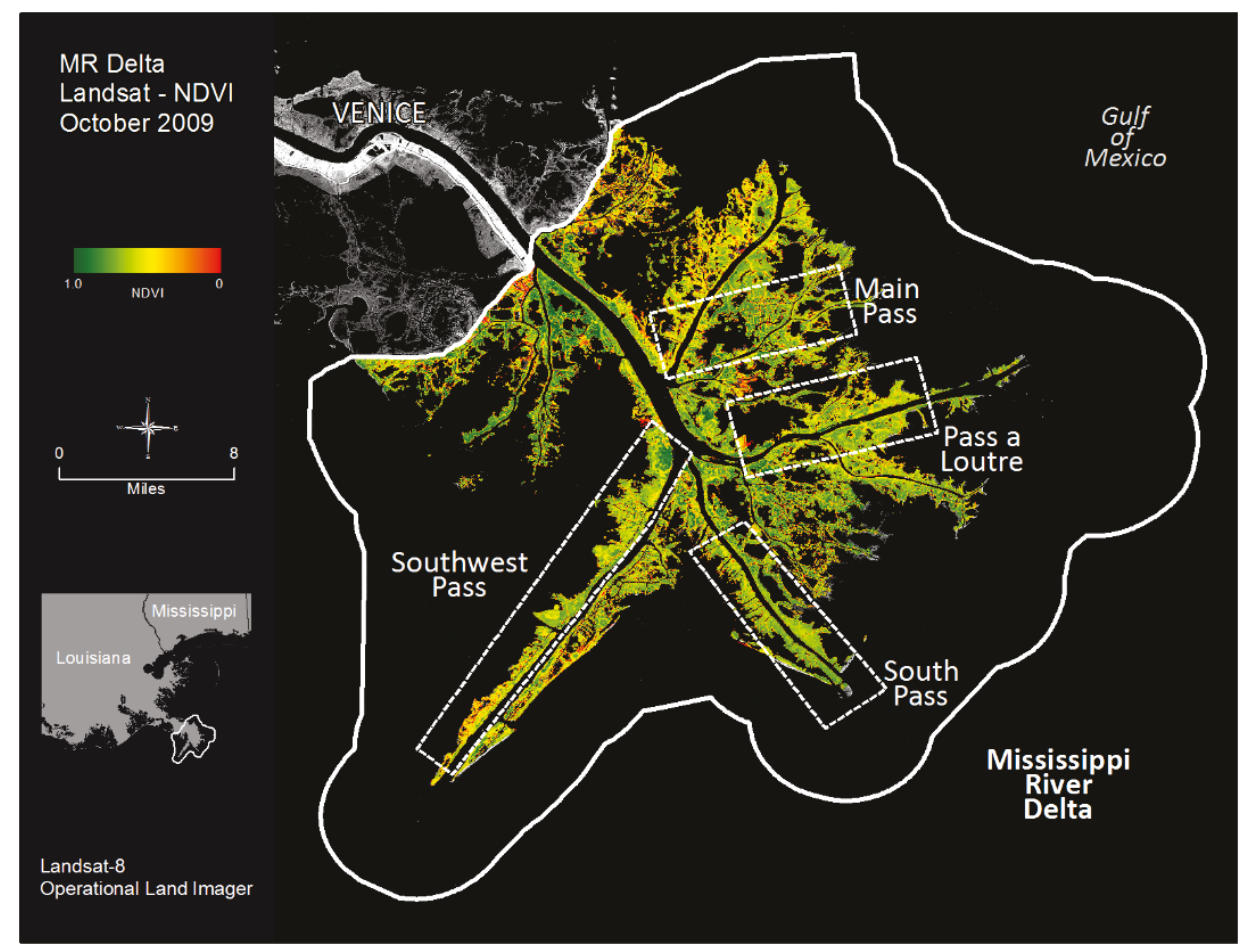

Figure B-6. February 2010 Landsat-8-derived NDVI of vegetation within the Mississippi River Delta and project AOI.

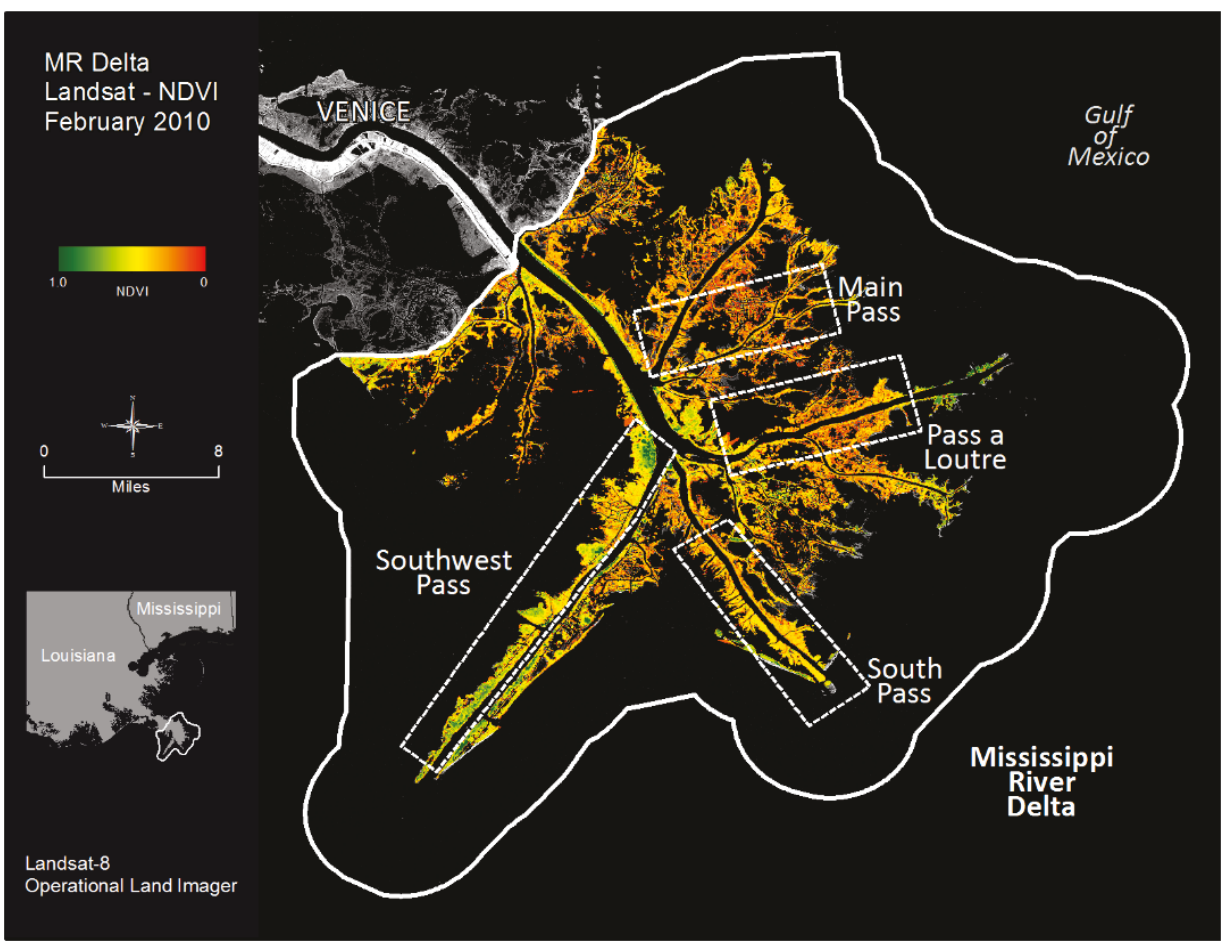


Figure B-7. September 2010 Landsat-8-derived NDVI of vegetation within the Mississippi River Delta and project AOI.

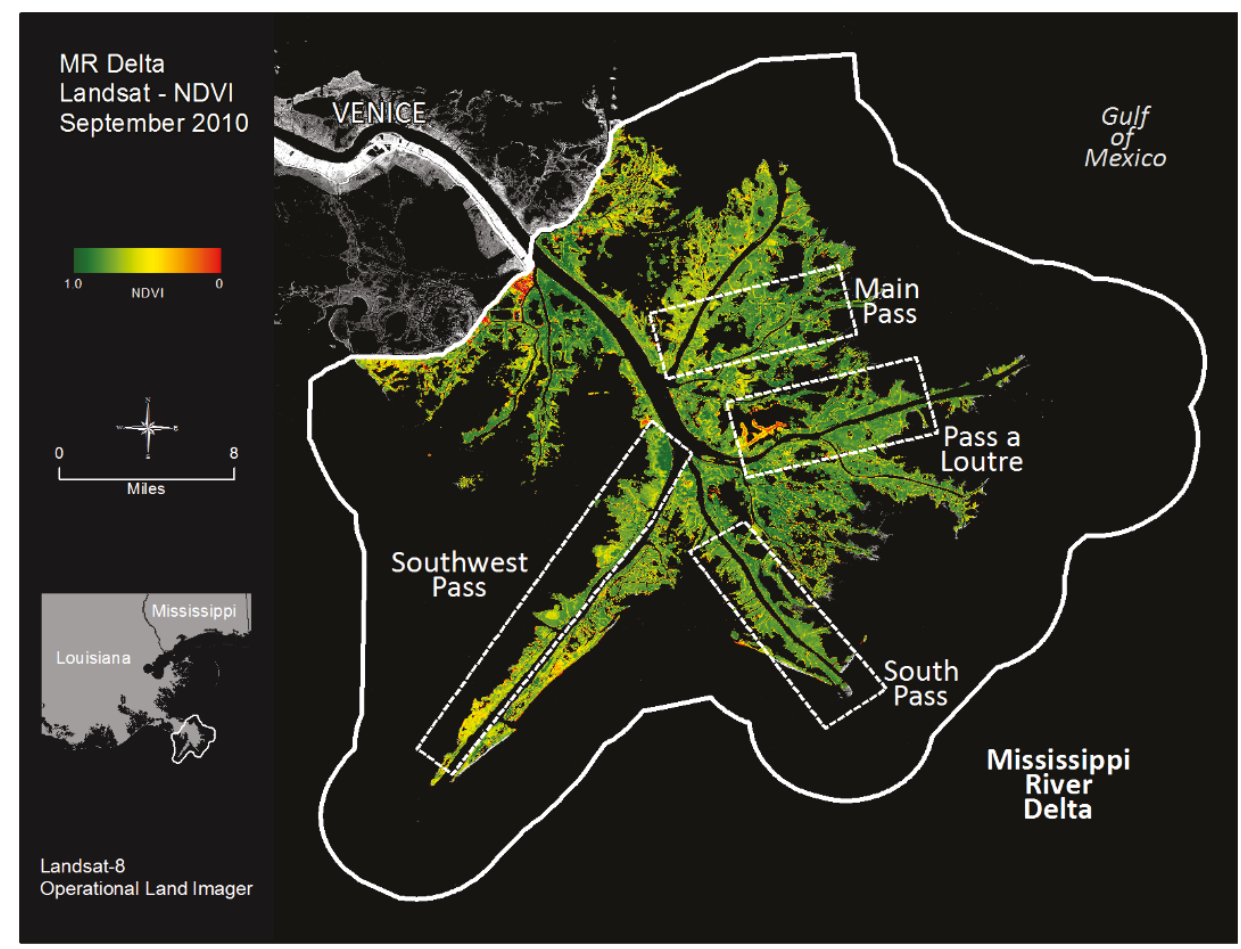

Figure B-8. March 2011 Landsat-8-derived NDVI of vegetation within the Mississippi River Delta and project AOI.

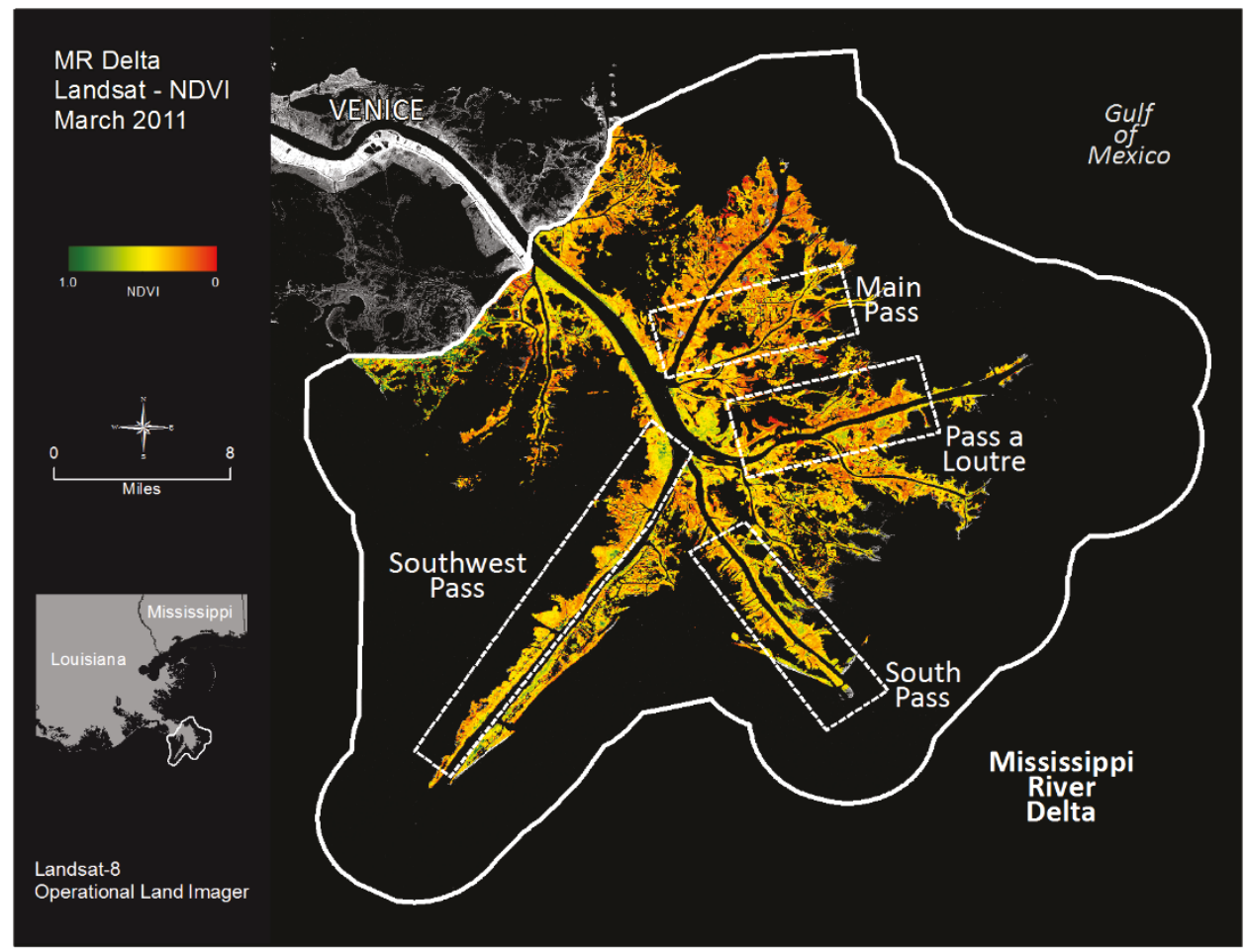


Figure B-9. April 2011 Landsat-8-derived NDVI of vegetation within the Mississippi River Delta and project AOI.

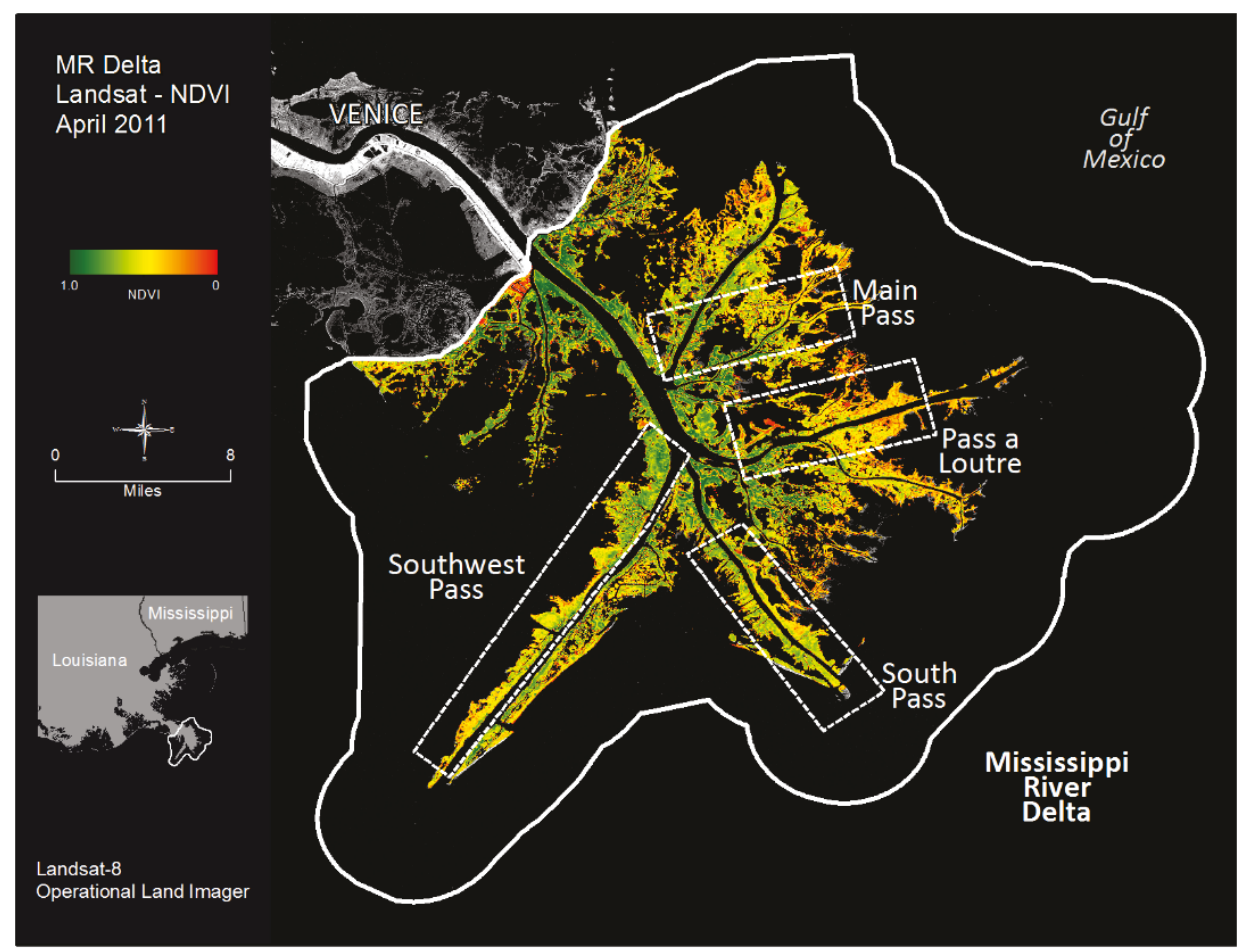

Figure B-10. June 2011 Landsat-8-derived NDVI of vegetation within the Mississippi River Delta and project AOI.

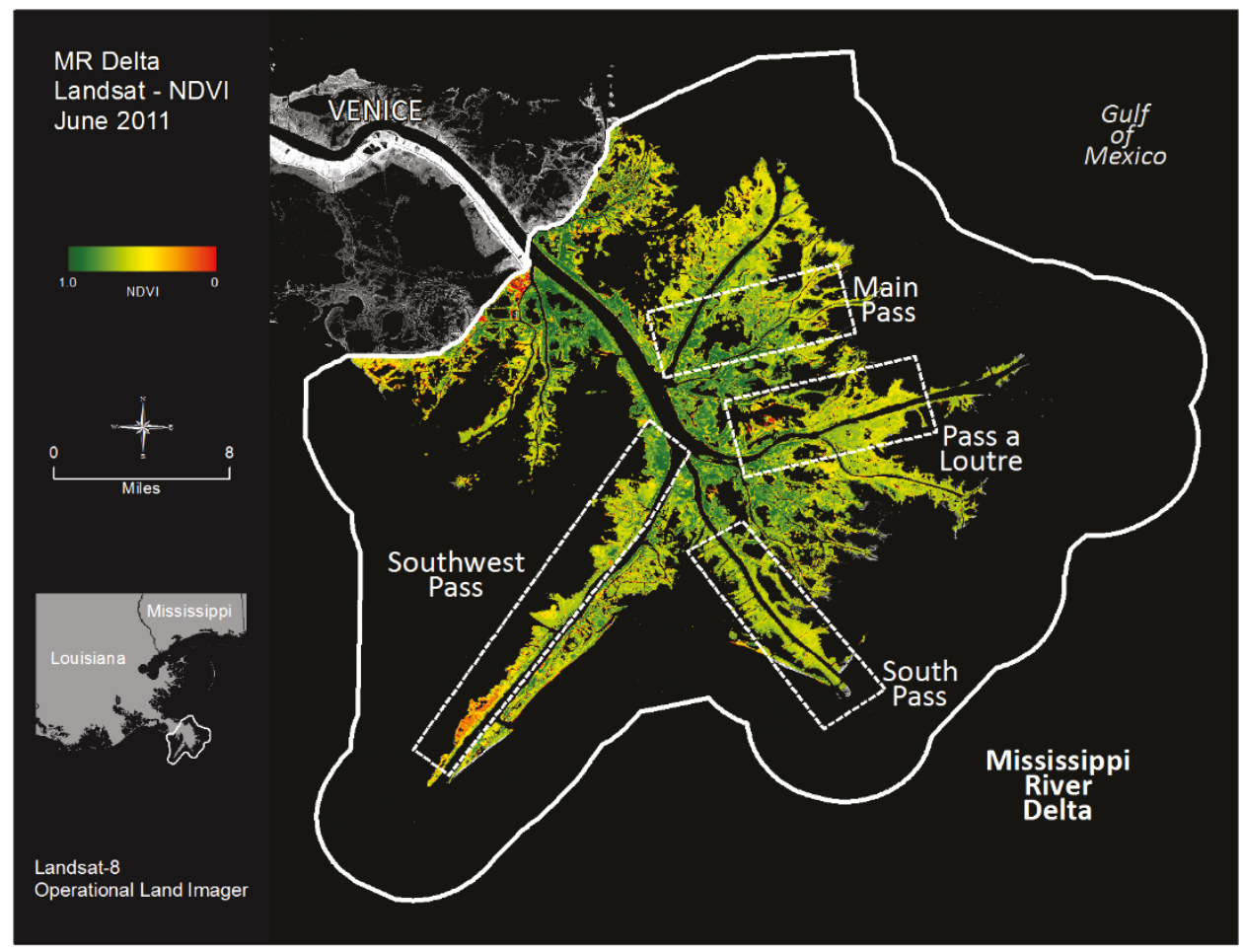


Figure B-11. September 2011 Landsat-8-derived NDVI of vegetation within the Mississippi River Delta and project AOI.

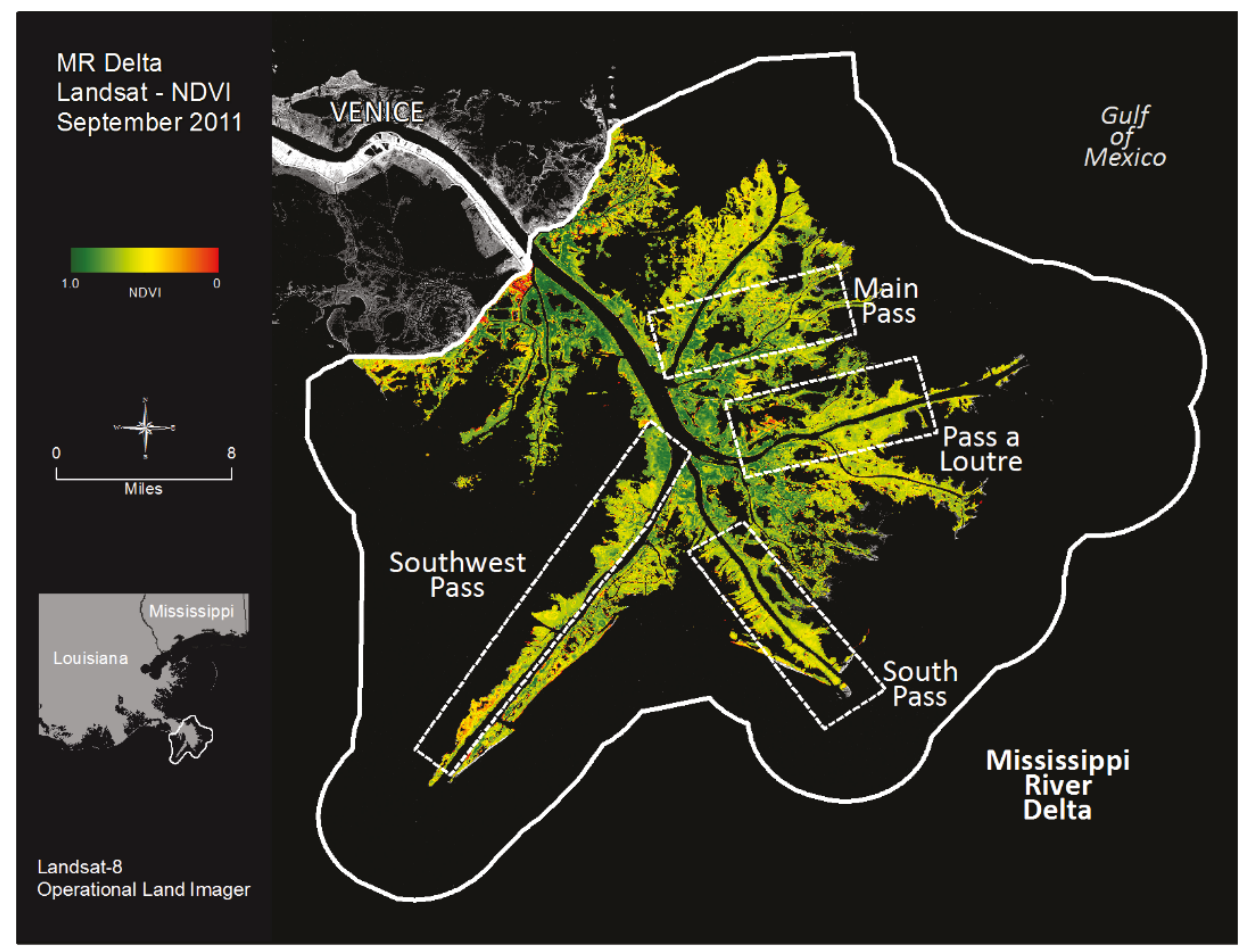

Figure B-12. December 2013 Landsat-8-derived NDVI of vegetation within the Mississippi River Delta and project AOI.

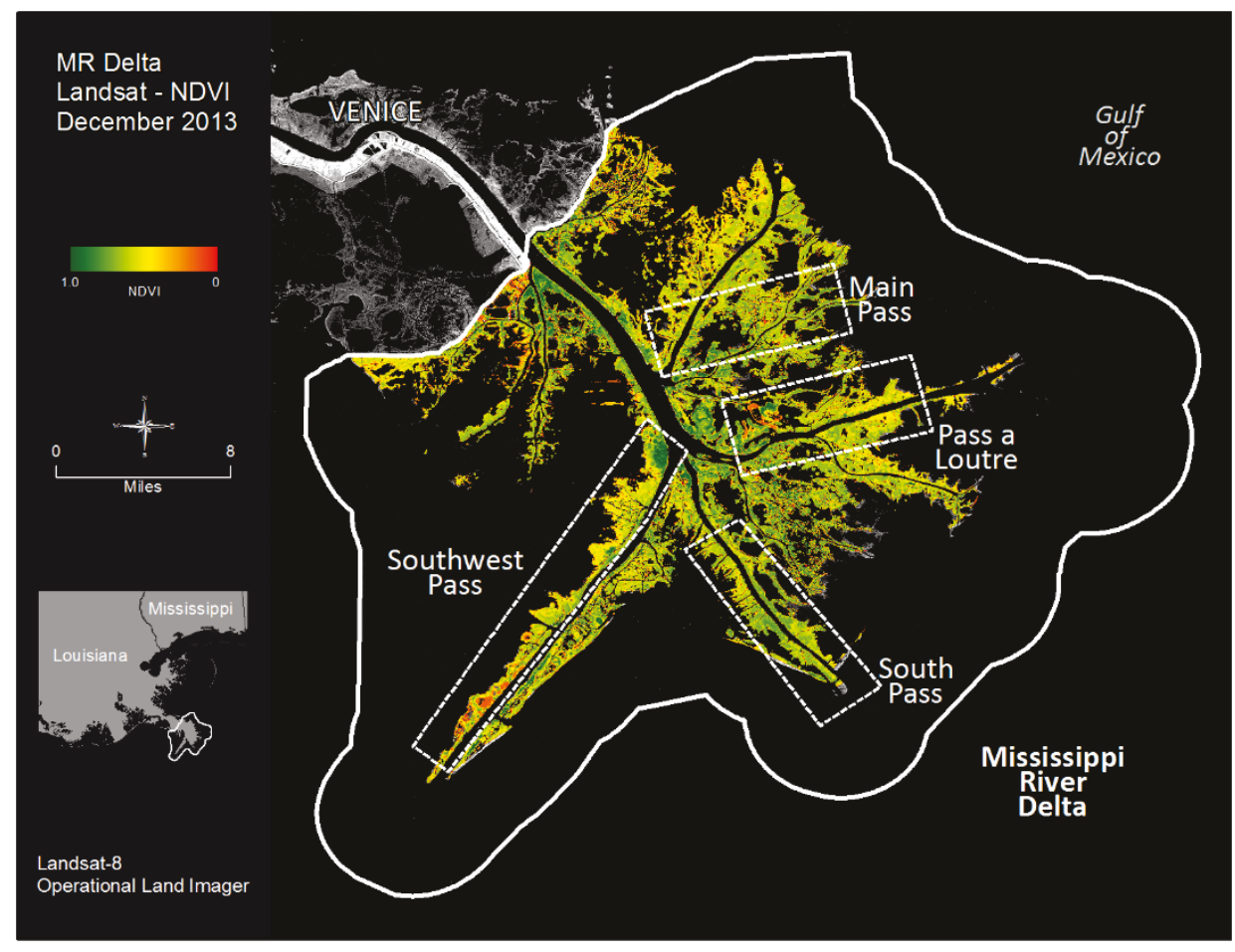


Figure B-13. April 2014 Landsat-8-derived NDVI of vegetation within the Mississippi River Delta and project AOI.

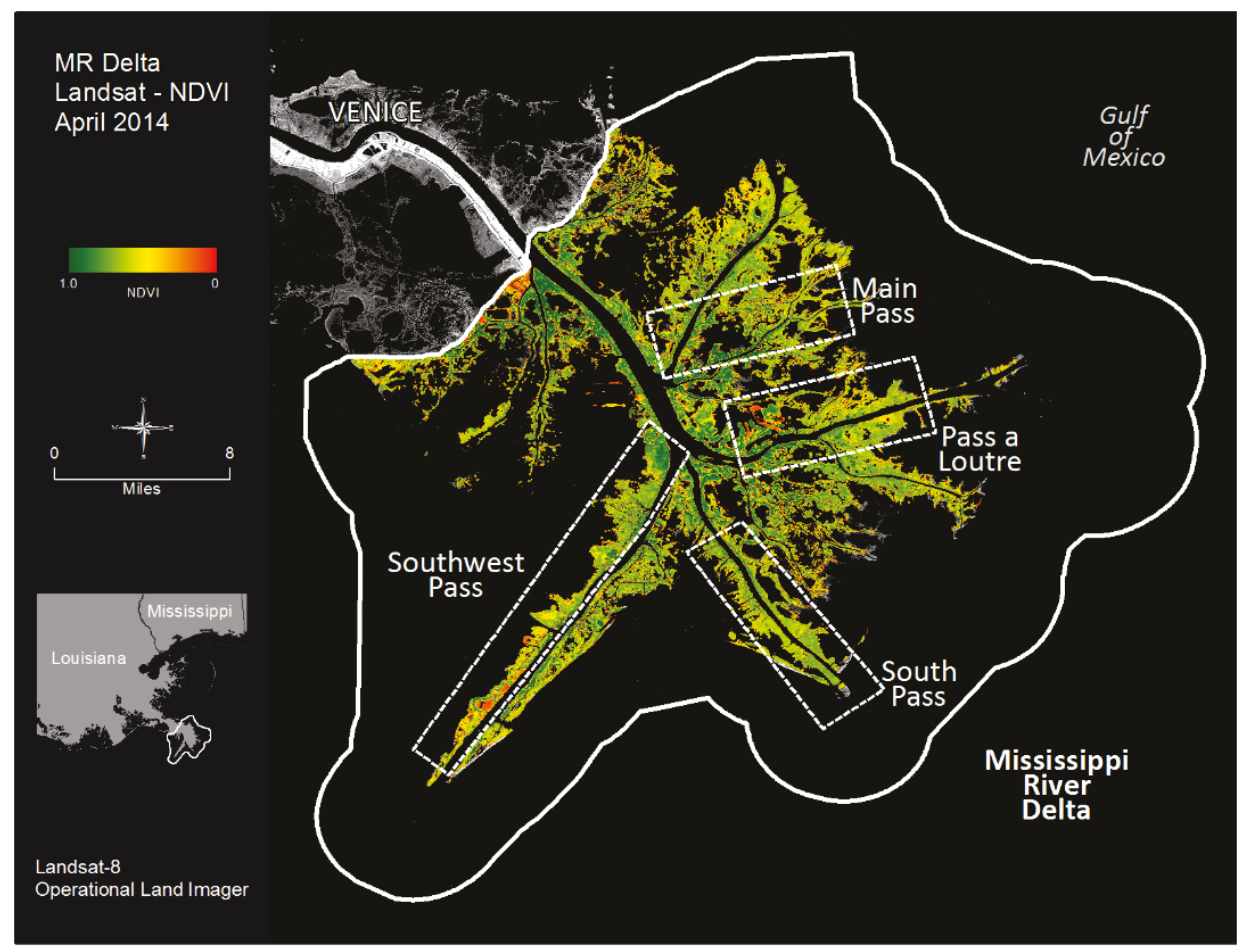

Figure B-14. November 2014 Landsat-8-derived NDVI of vegetation within the Mississippi River Delta and project AOI.

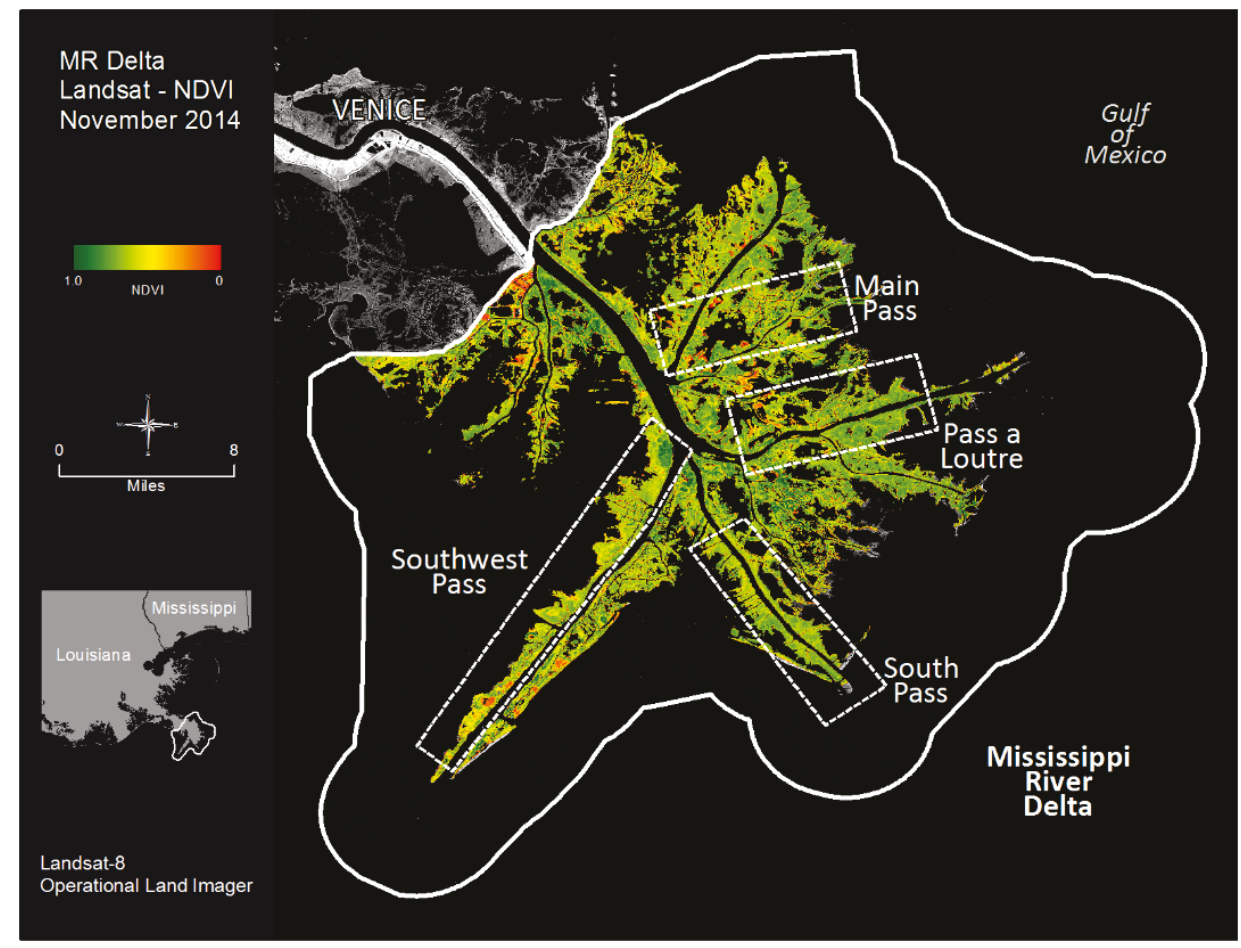


Figure B-15. January 2015 Landsat-8-derived NDVI of vegetation within the Mississippi River Delta and project AOI.

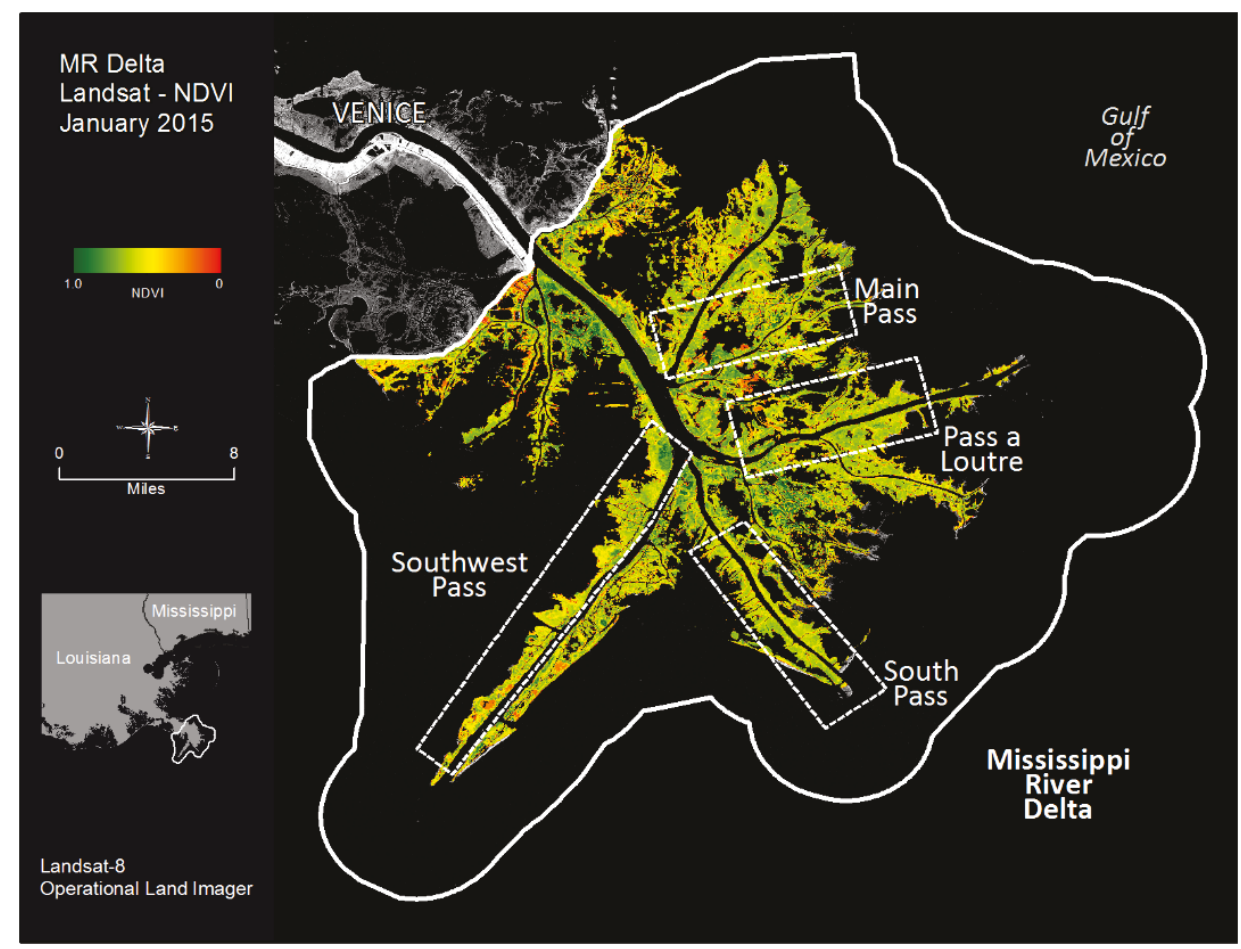

Figure B-16. August 2015 Landsat-8-derived NDVI of vegetation within the Mississippi River Delta and project AOI.

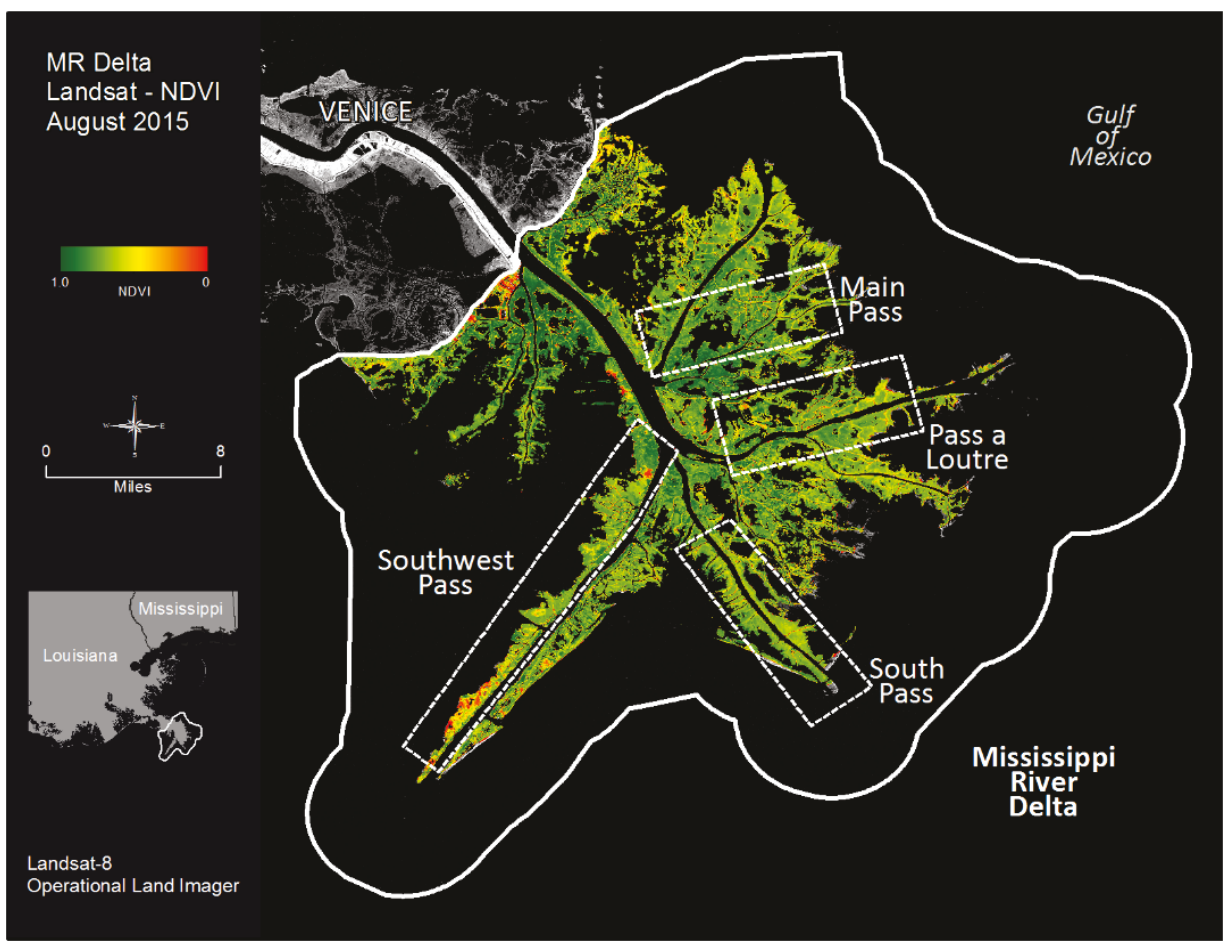


Figure B-17. January 2016 Landsat-8-derived NDVI of vegetation within the Mississippi River Delta and project AOI.

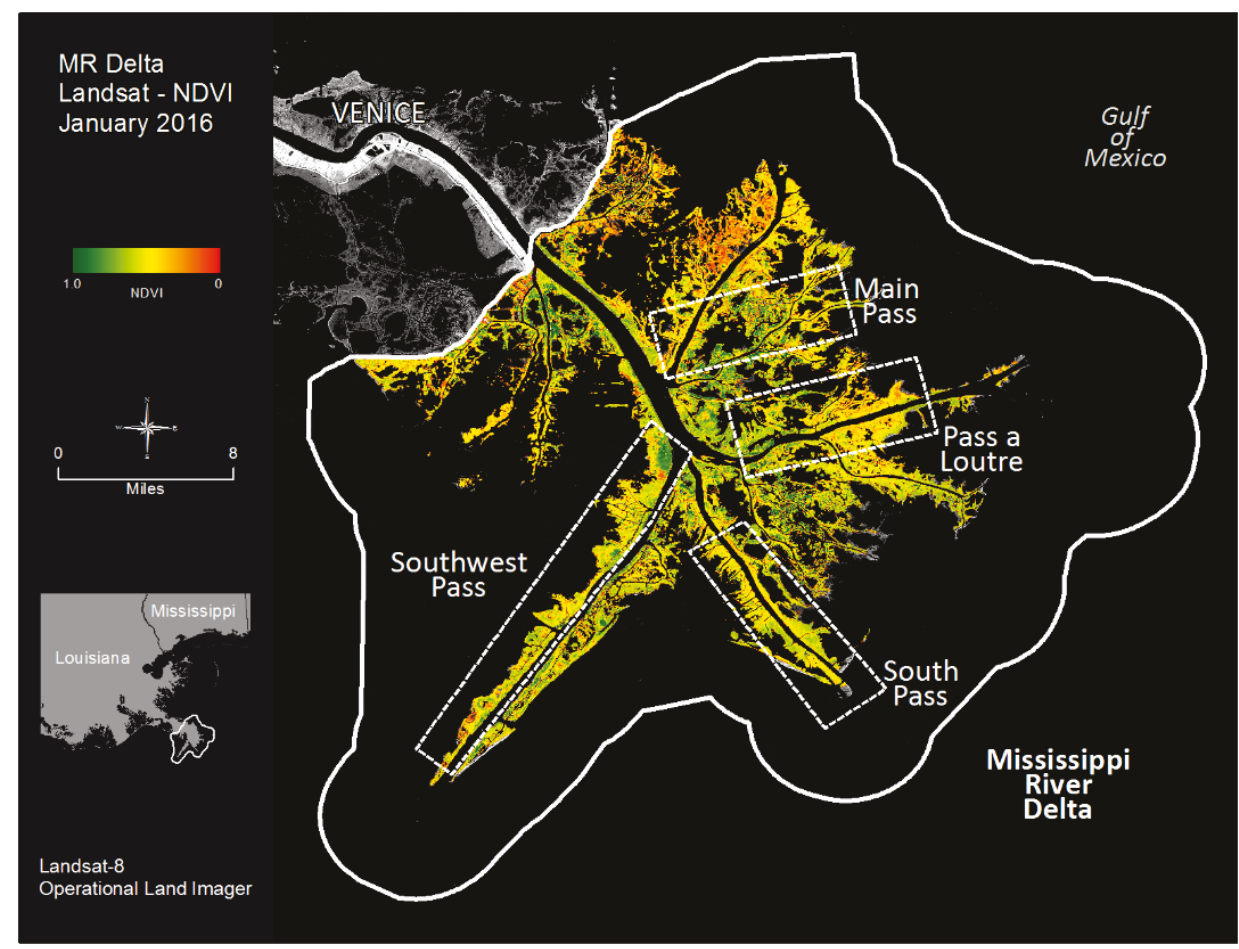

Figure B-18. February 2016 Landsat-8-derived NDVI of vegetation within the Mississippi River Delta and project AOI.

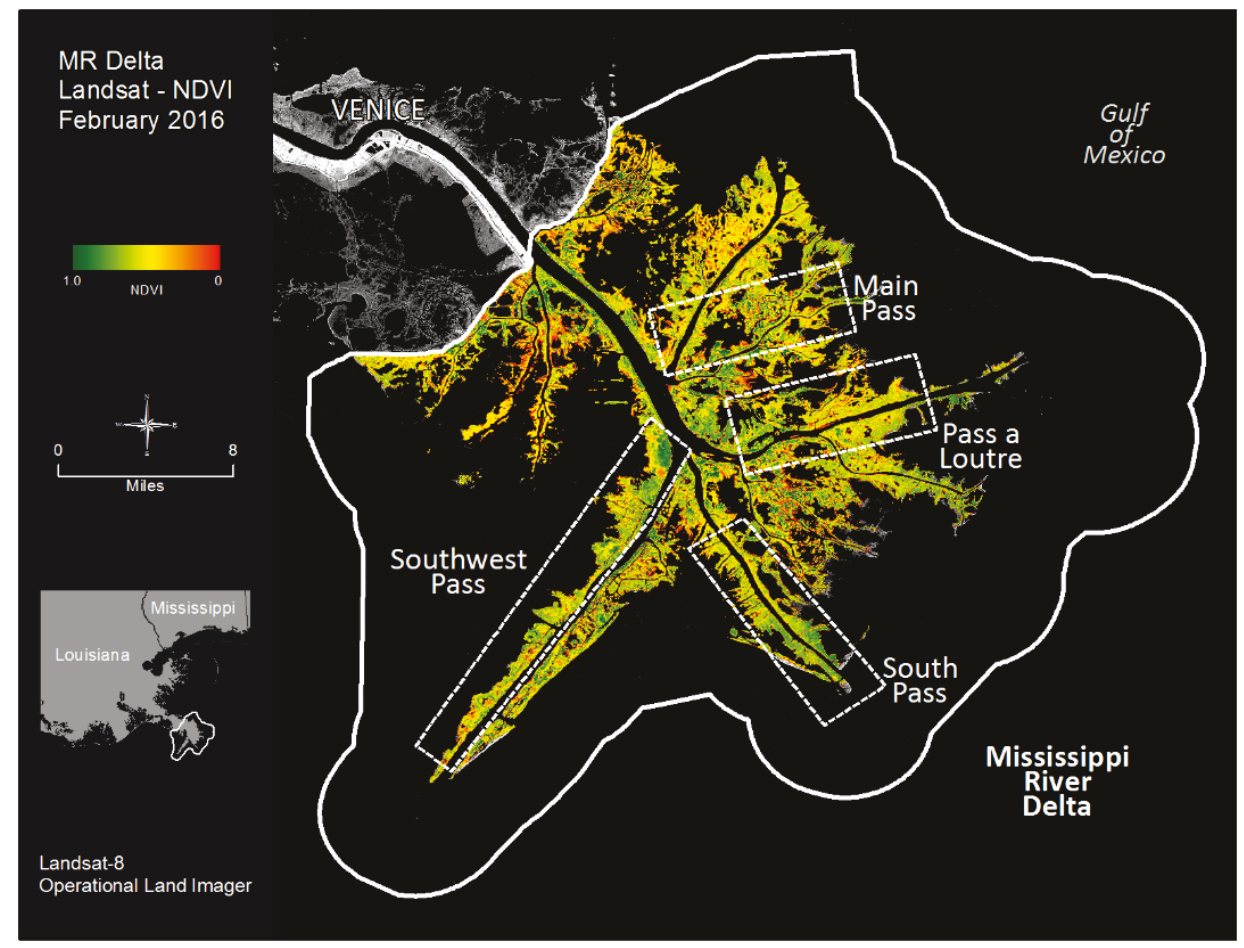


Figure B-19. March 2016 Landsat-8-derived NDVI of vegetation within the Mississippi River Delta and project AOI.

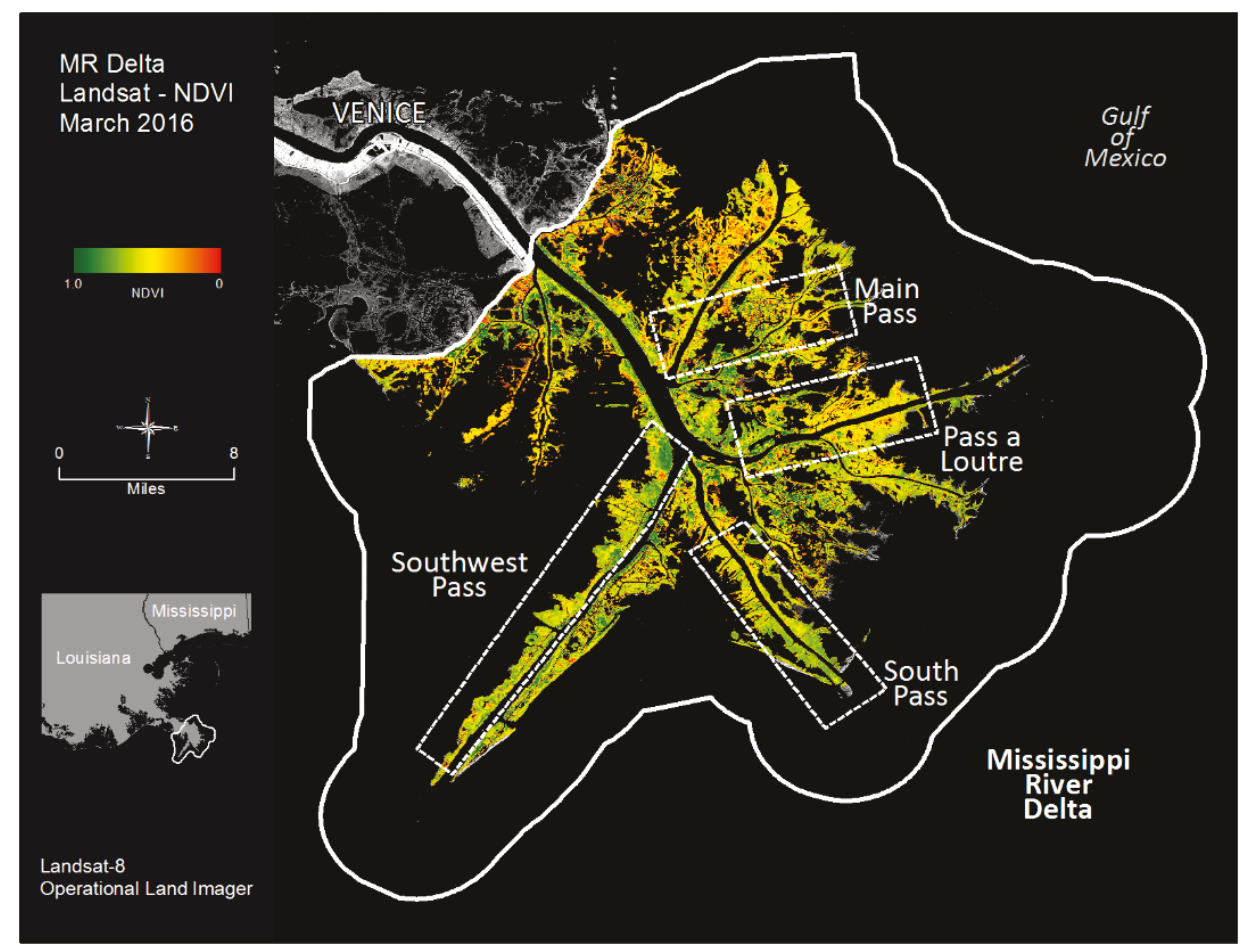

Figure B-20. March 2017 Landsat-8-derived NDVI of vegetation within the Mississippi River Delta and project AOI.

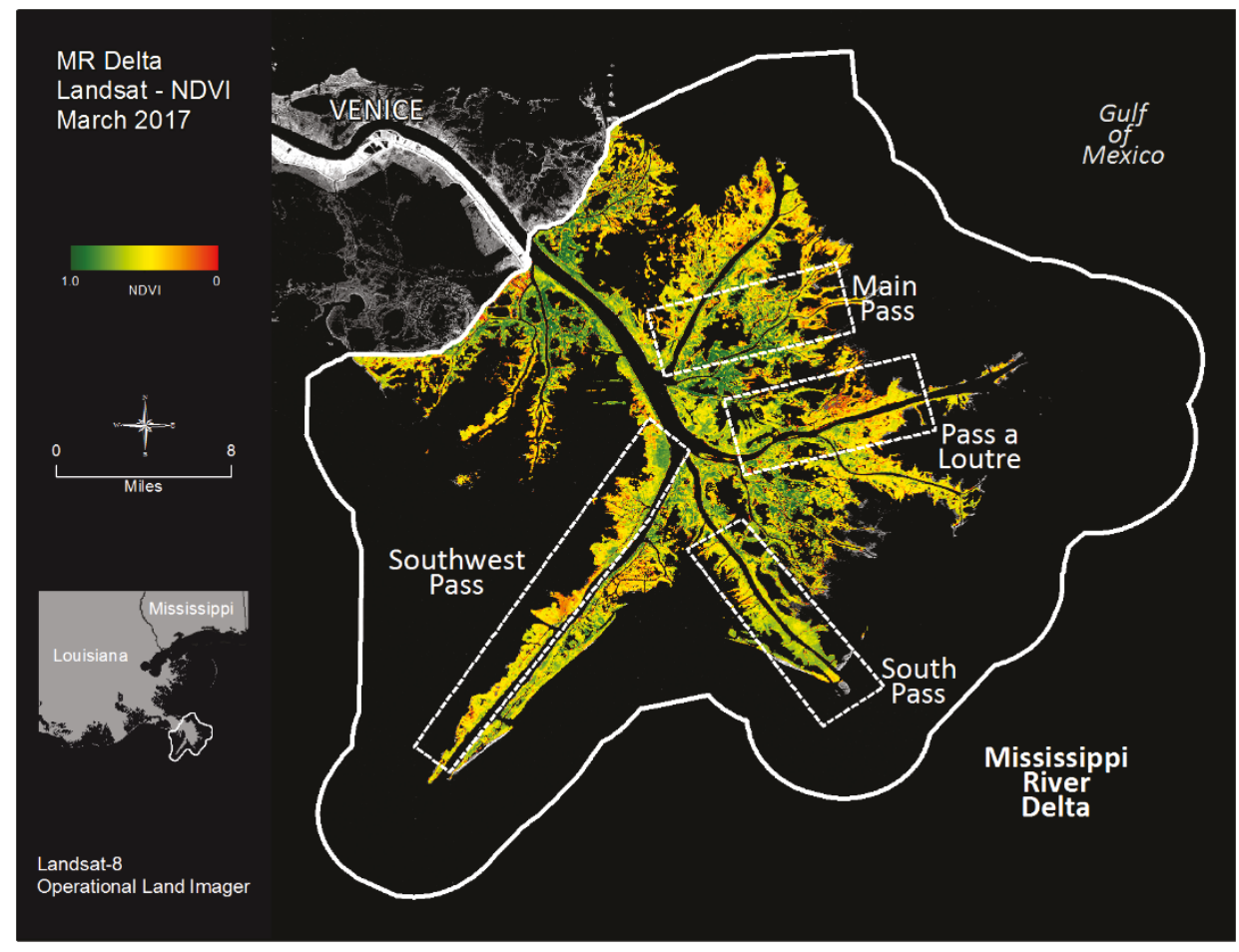




\section{Landsat-Derived NDVI Difference}

Figure B-21. Change analysis based on Landsat-8 derived NDVI of vegetation within the MRD from October 2008 to October 2009.

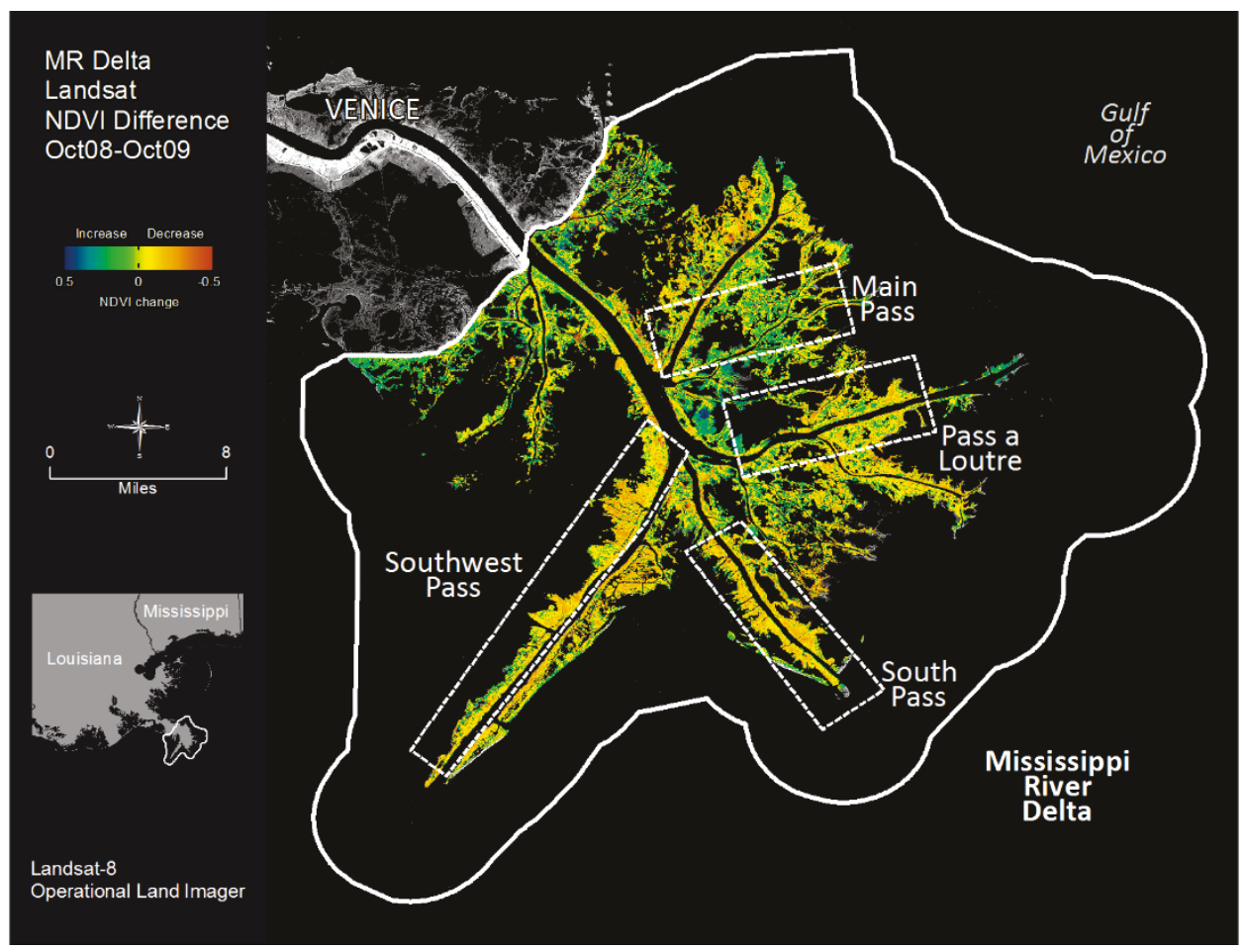

Figure B-22. Change analysis based on Landsat-8 derived NDVI of vegetation within the MRD from October 2009 to September 2010.

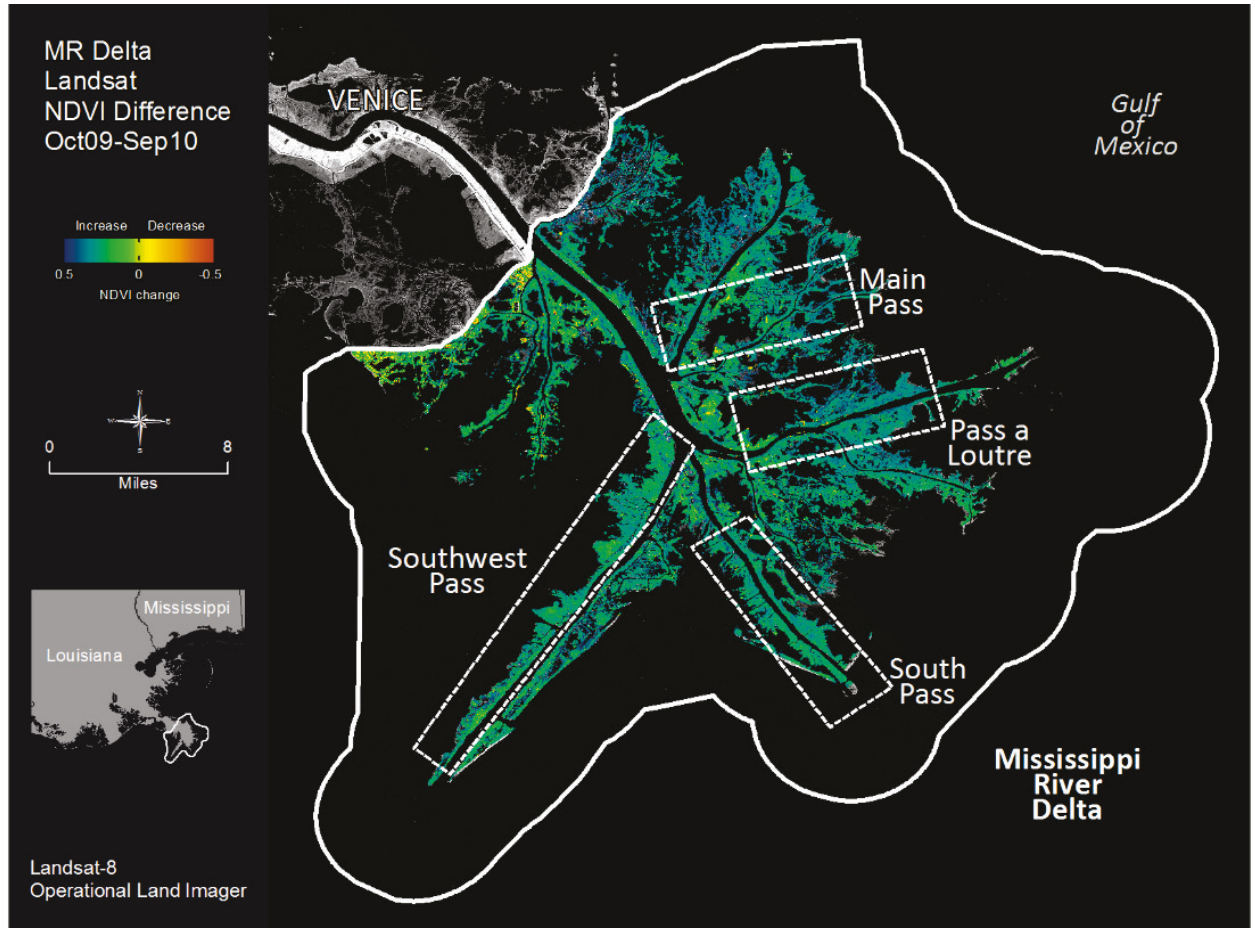


Figure B-23. Change analysis based on Landsat-8 derived NDVI of vegetation within the MRD from September 2010 to September 2011.

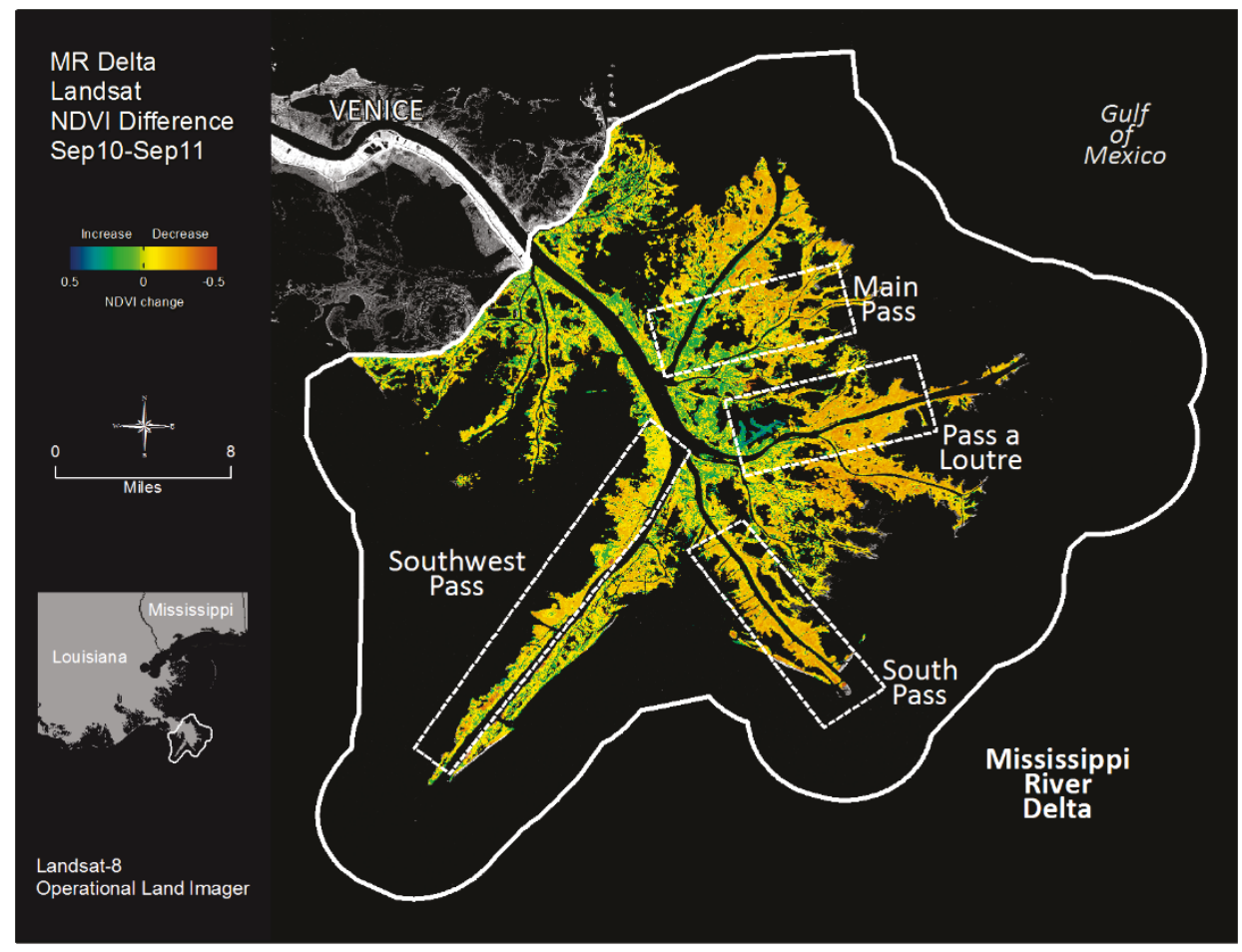

Figure B-24. Change analysis based on Landsat-8 derived NDVI of vegetation within the MRD from September 2011 to December 2013.

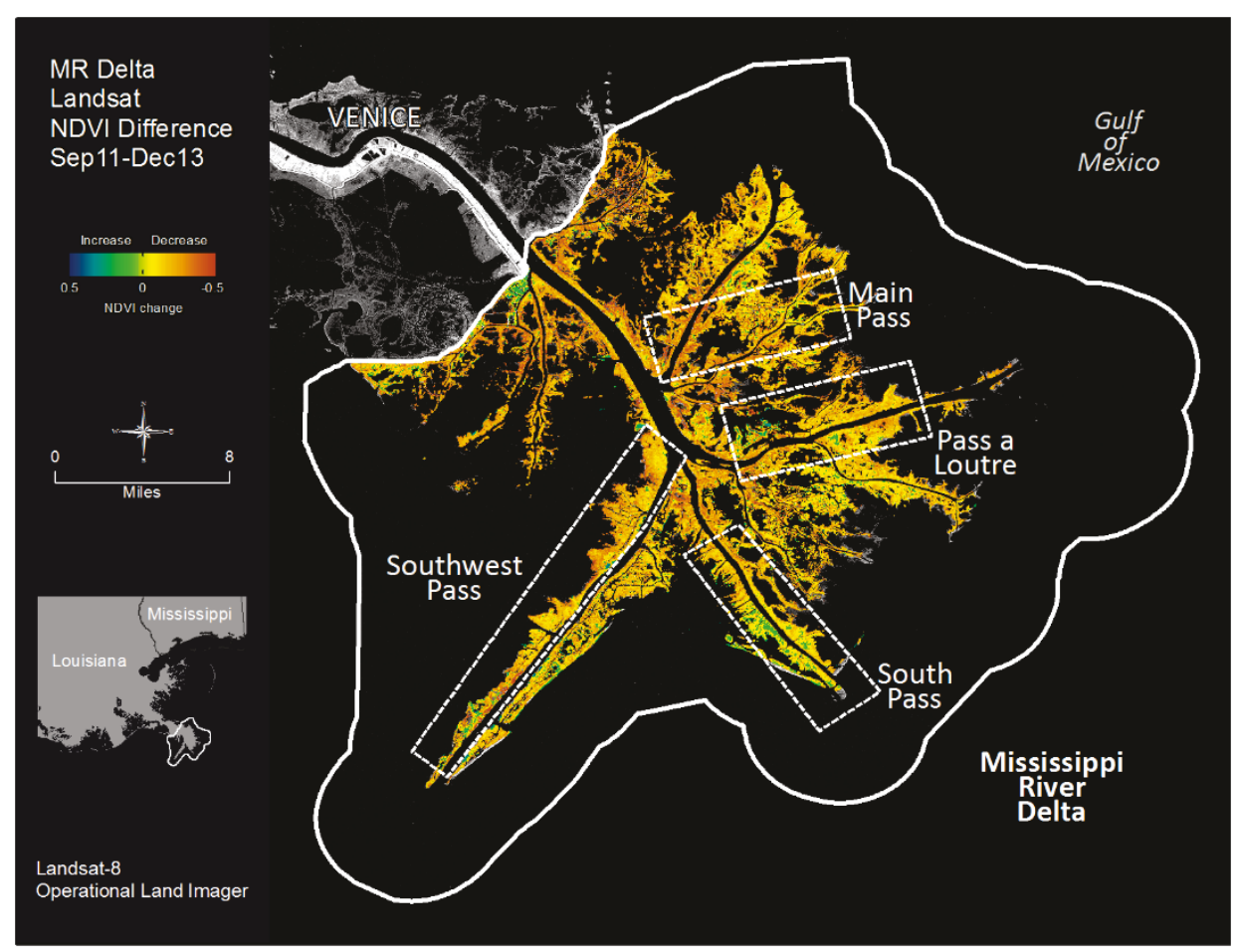


Figure B-25. Change analysis based on Landsat-8 derived NDVI of vegetation within the MRD from December 2013 to November 2014.

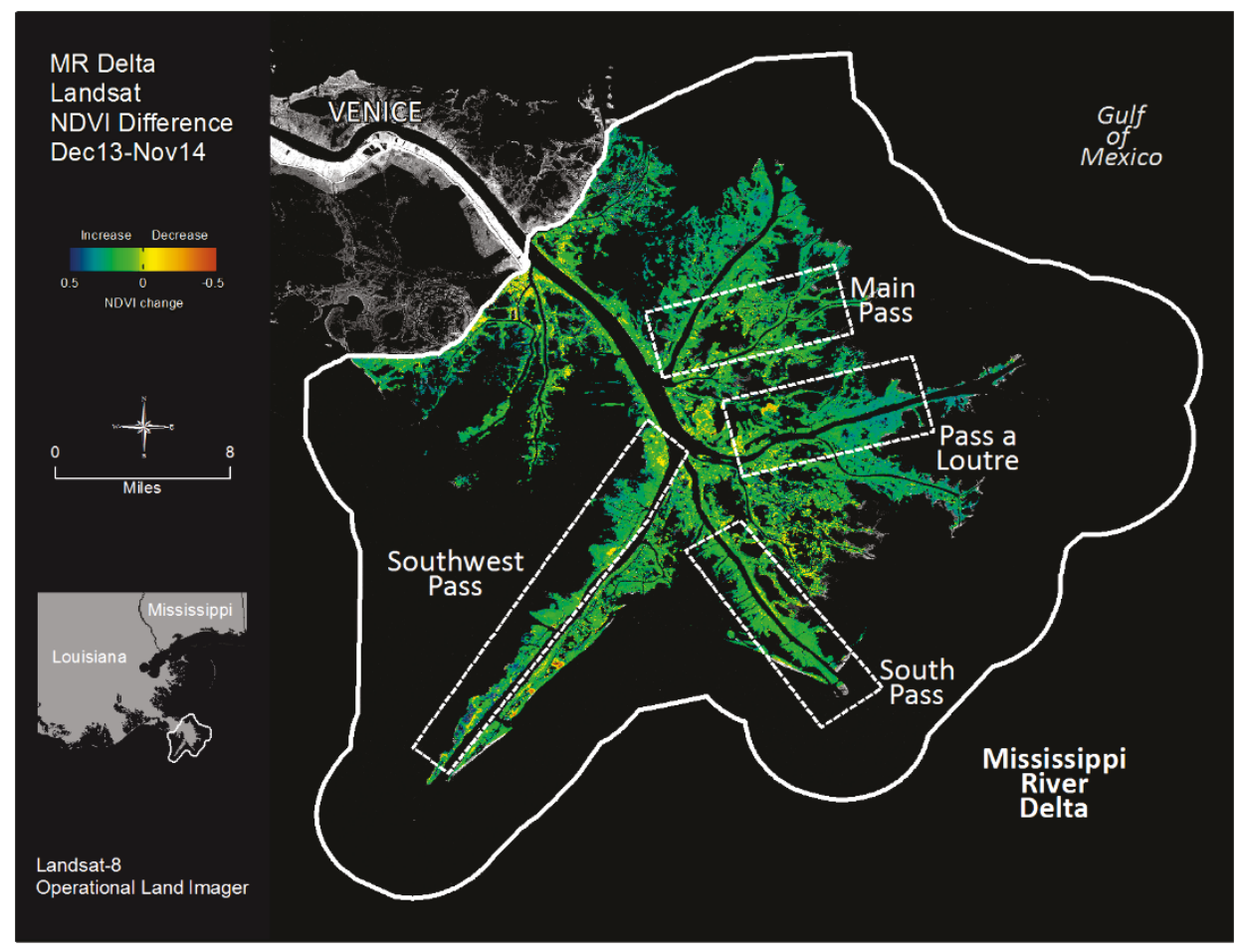

Figure B-26. Change analysis based on Landsat-8 derived NDVI of vegetation within the MRD from November 2014 to October 2015.




Figure B-27. Change analysis based on Landsat-8 derived NDVI of vegetation within the MRD from March 2016 to March 2017.

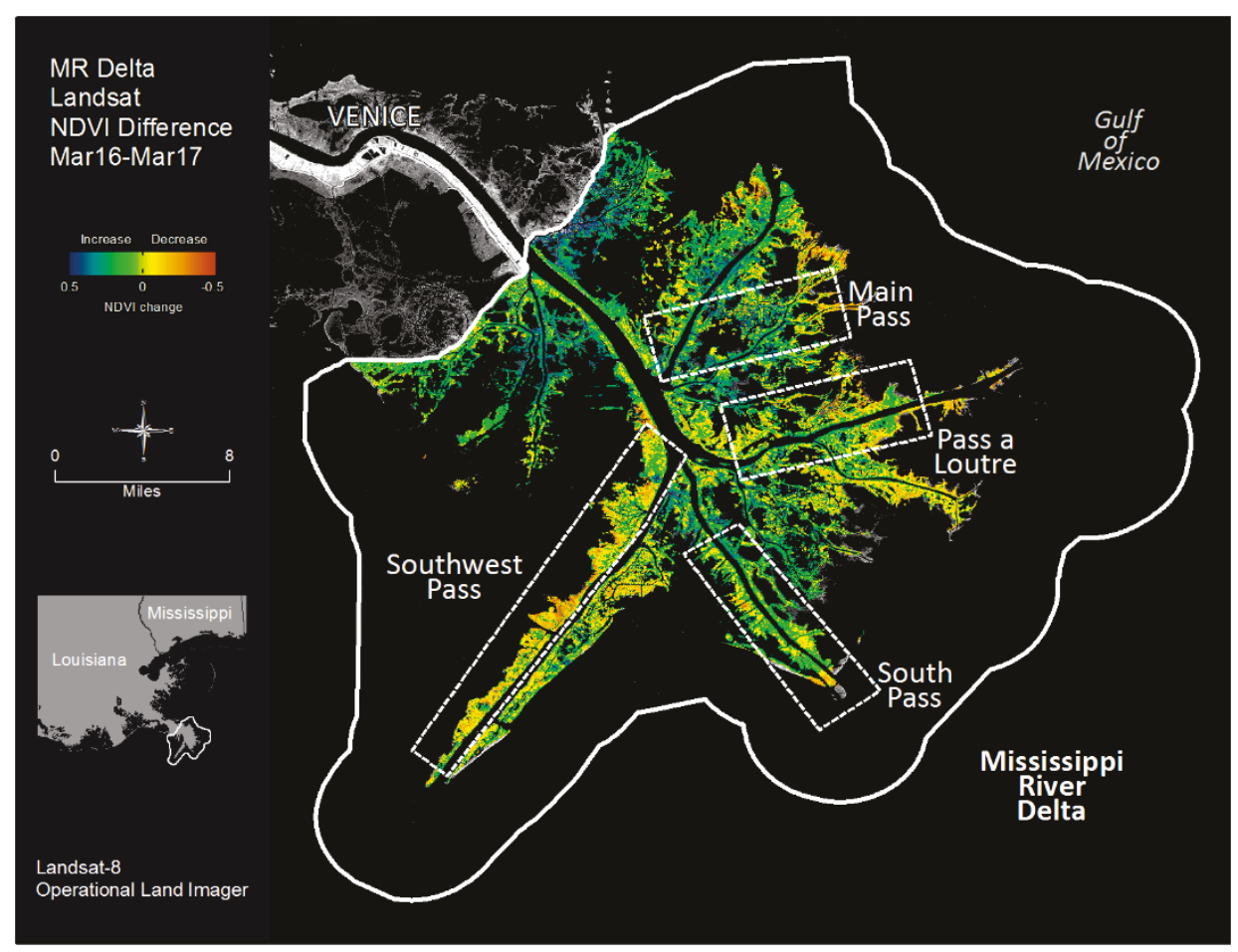




\section{Appendix C: WV-Derived NDVI}

\section{WV-Derived NDVI}

Figure C-1. October 2012 WV-derived NDVI of vegetation within the Pass a Loutre project area.

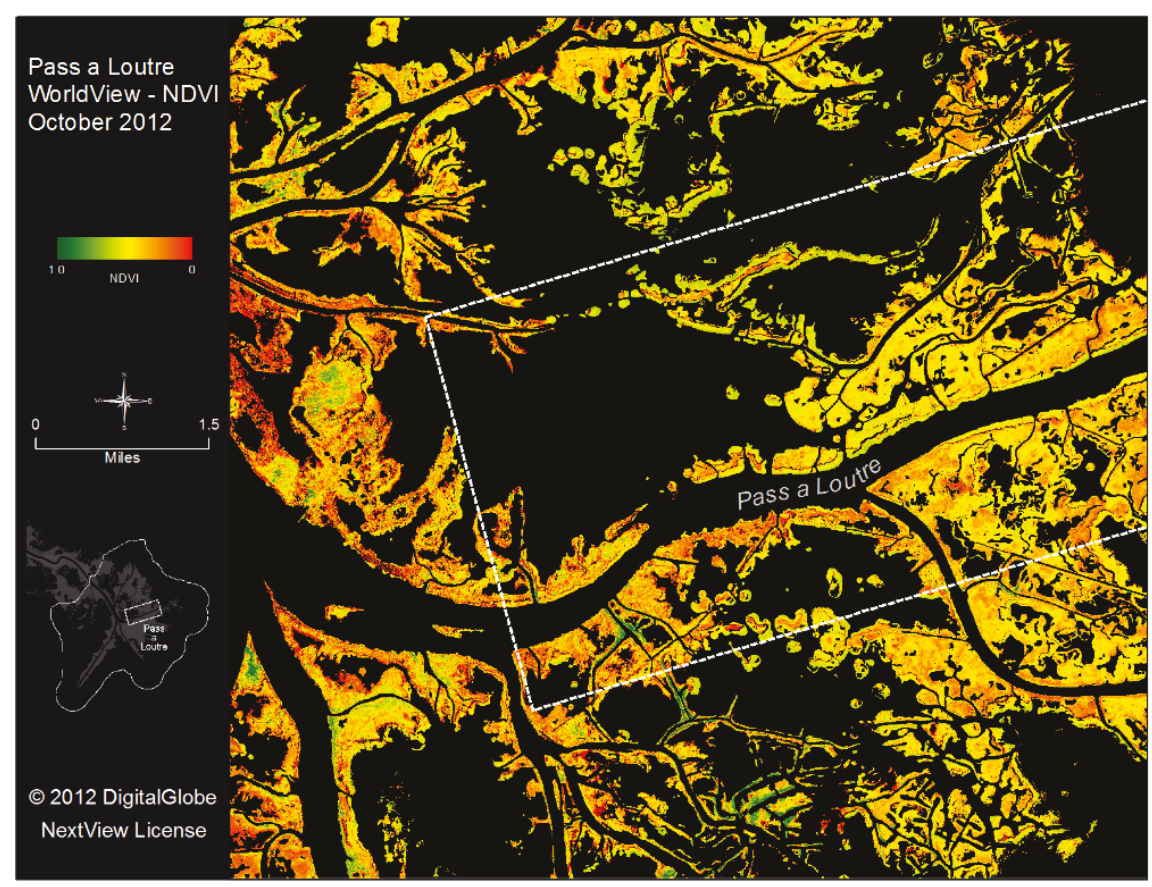

Figure C-2. August 2017 WV-derived NDVI of vegetation within the Pass a Loutre project area.

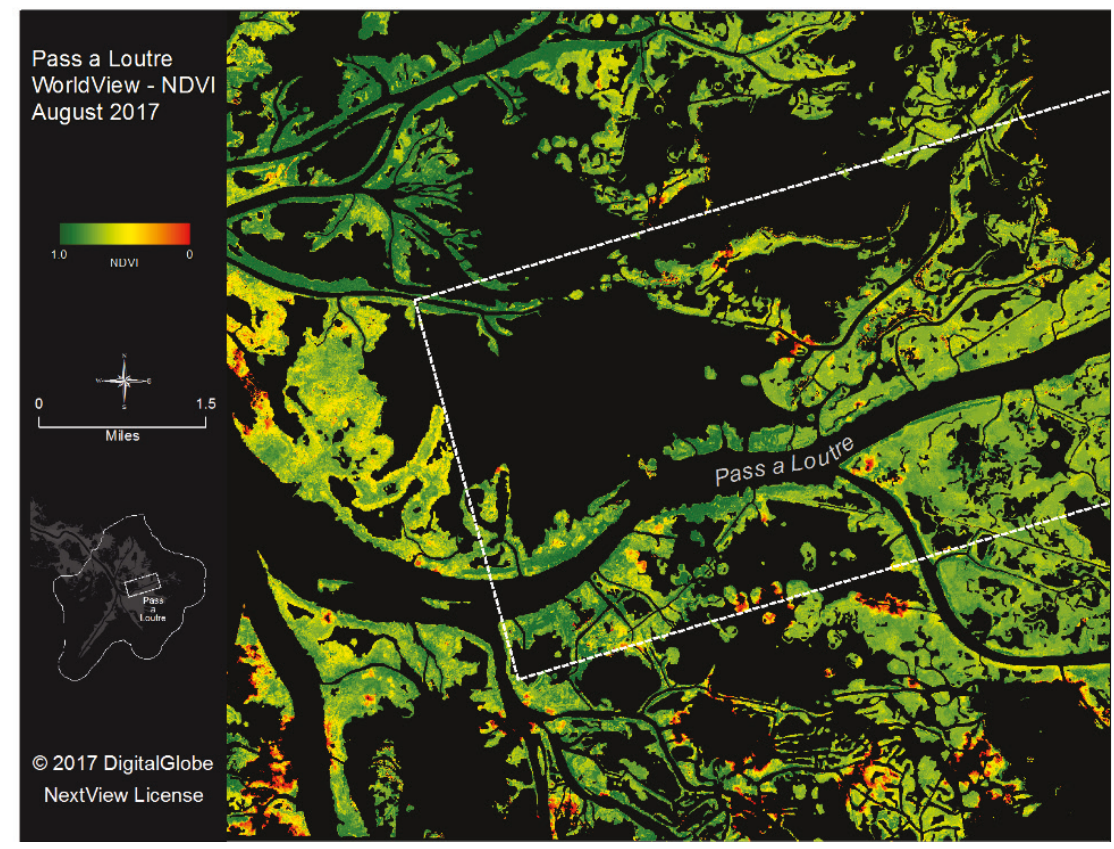




\section{WV-Derived NDVI Difference}

Figure C-3. Change analysis based on WV-derived NDVI of vegetation within the Pass a Loutre assessment area from October 2012 to November 2014.

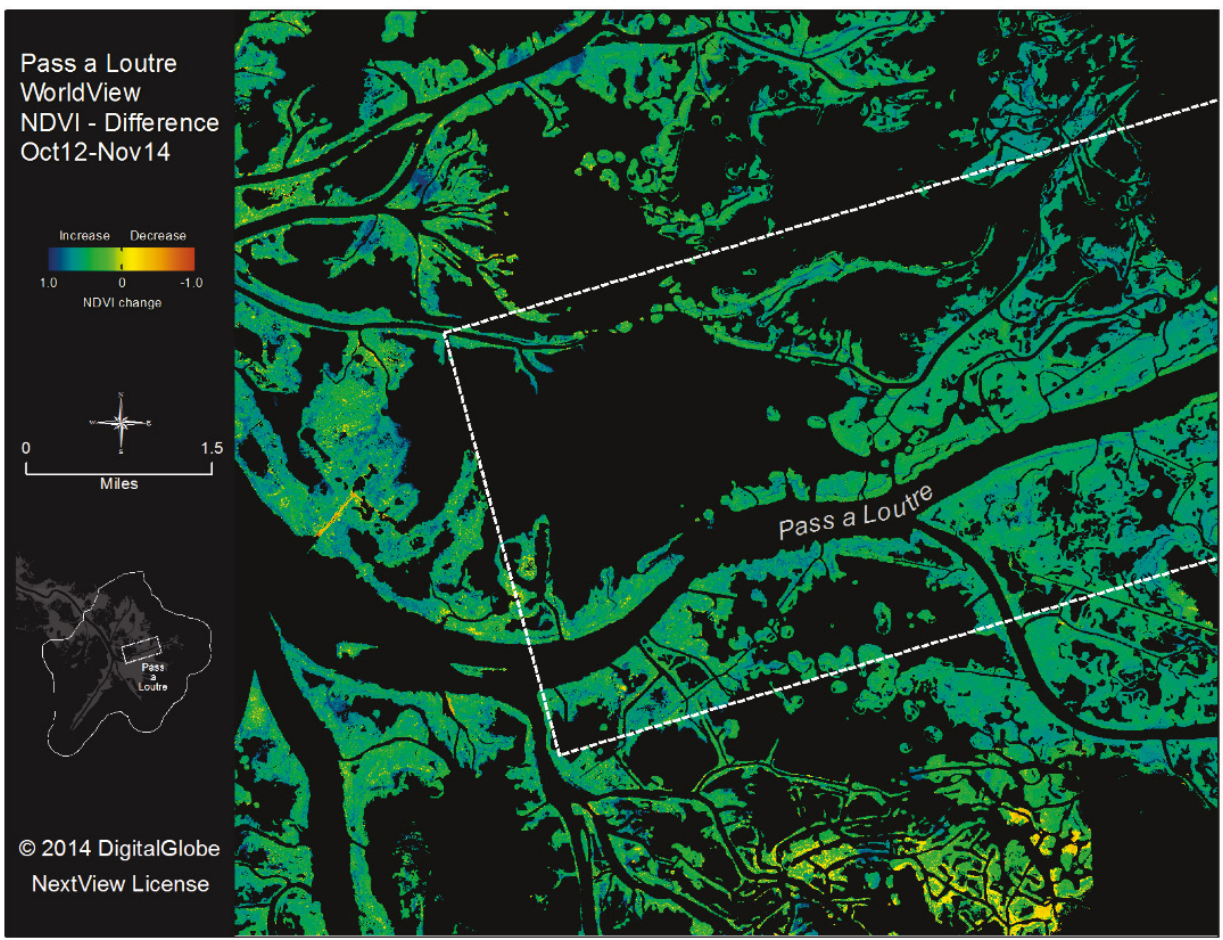

Figure C-4. Change analysis based on WV-derived NDVI of vegetation within the Pass a Loutre assessment area from October 2016 to August 2017.

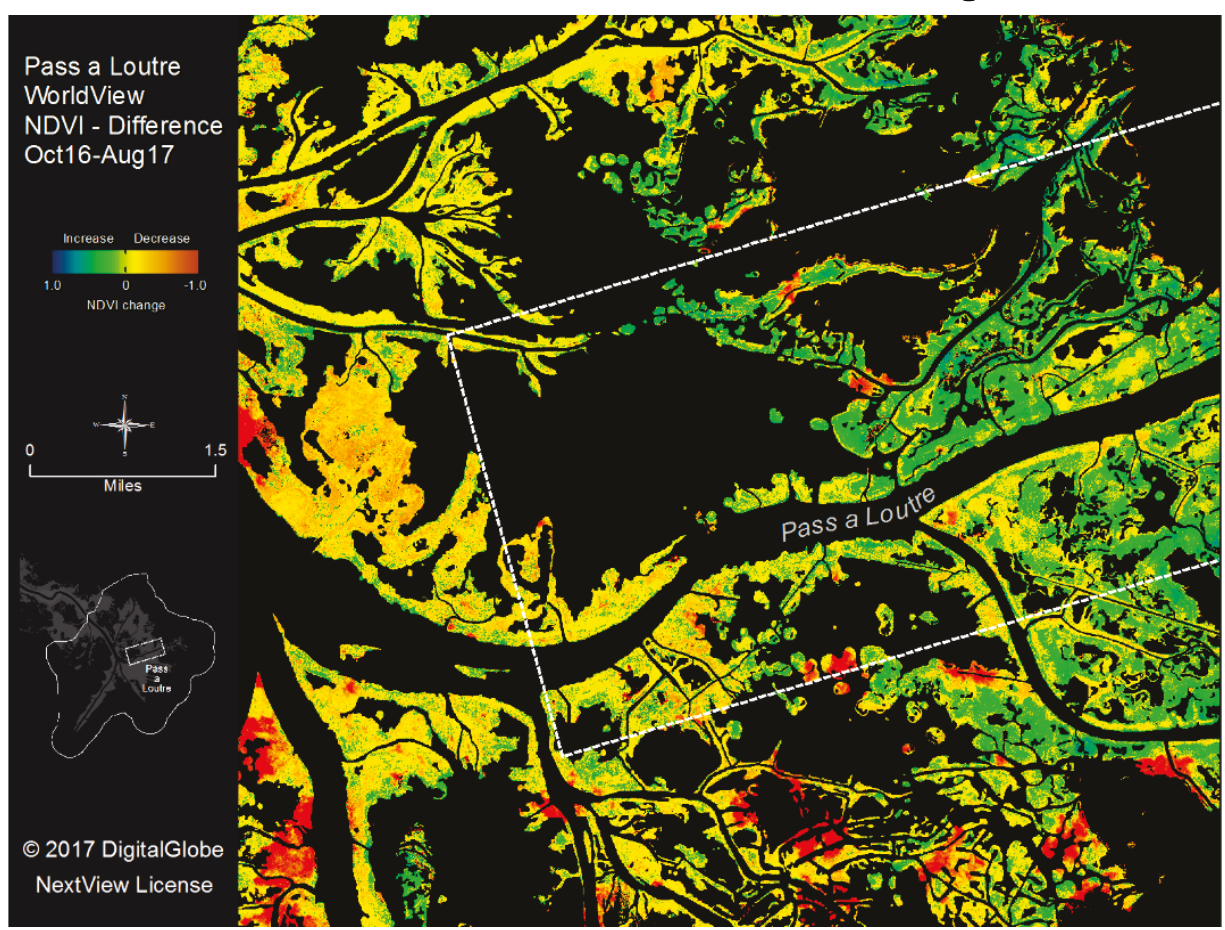




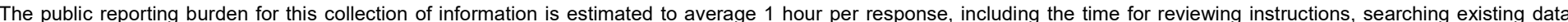

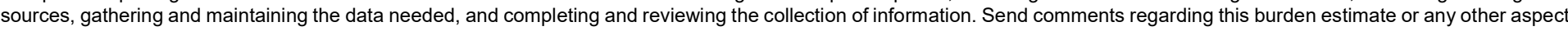

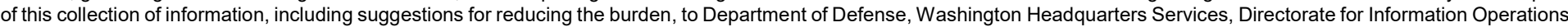

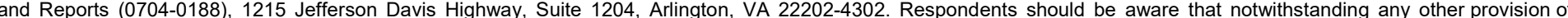
law, no person shall be subject to any penalty for failing to comply with a collection of information if it does not display a currently valid OMB control number.

PLEASE DO NOT RETURN YOUR FORM TO THE ABOVE ADDRESS.

\begin{tabular}{|c|c|c|}
\hline $\begin{array}{l}\text { 1. REPORT DATE } \\
\text { August } 2018\end{array}$ & $\begin{array}{l}\text { 2. REPORT TYPE } \\
\text { Final Report }\end{array}$ & 3. DATES COVERED (From - To) \\
\hline
\end{tabular}

Final Report

\section{TITLE AND SUBTITLE}

Geospatial Assessments of Phragmites australis Die-Off in South Louisiana: Preliminary

Findings

5a. CONTRACT NUMBER

5b. GRANT NUMBER

5c. PROGRAM ELEMENT NUMBER

5d. PROJECT NUMBER

462030

Glenn M. Suir, Christina L. Saltus, Molly K. Reif 5e. TASK NUMBER

5f. WORK UNIT NUMBER

8. PERFORMING ORGANIZATION REPORT NUMBER

ERDC/EL TR-18-9

10. SPONSOR/MONITOR'S ACRONYM(S)

USACE

11. SPONSOR/MONITOR'S REPORT NUMBER(S)

\section{DISTRIBUTION/AVAILABILITY STATEMENT}

Approved for public release; distribution is unlimited.

\section{SUPPLEMENTARY NOTES}

\section{ABSTRACT}

The Lower Mississippi River Delta (MRD) is dominated by Phragmites australis which provides a stabilizing force, protecting marsh communities from erosion and storm-related impacts. Starting in 2016, massive die-offs of Phragmites were first observed in the MRD coinciding with observations of Nipponaclerda biwakoensis (Phragmites scale), an exotic insect originating from Asia. Concurrent with the insect invasion, many previously healthy stands have died or experienced stunted growth, resulting in conversion to understory species or to open water features. This study utilized remote sensing methods to assess vegetation in scale-impacted areas of the MRD. The Normalized Difference Vegetation Index (NDVI) was used to evaluate historical changes in vegetation health, and species classifications were used to discriminate Phragmites from non-target species to better understand vegetation impacts, especially in cases where Phragmites haplotype impacts may have differed. Moderate spatial resolution NDVI analyses provided rapid and cursory examinations of vegetation health while a proof of concept approach for differentiating Phragmites haplotypes and other species provided a preliminary way to assess potential species-specific stress or injury. These preliminary data show that extensive areas of Phragmites stands in the MRD were severely impacted (potentially by the scale) and some Phragmites haplotypes were more susceptible than others.

\section{SUBJECT TERMS}

Coasts-Louisiana, Introduced organisms_Environmental aspects, Marshes, Phragmites australis, Remote sensing

\section{SECURITY CLASSIFICATION OF:}

\begin{tabular}{l|c|c|c|c|} 
a. REPORT & b. ABSTRACT & c. THIS PAGE & ABSTRACT \\
Unclassified & Unclassified & Unclassified & SAR
\end{tabular}

18. NUMBER OF PAGES

51 19a. NAME OF RESPONSIBLE PERSON

Glenn M. Suir

19b. TELEPHONE NUMBER (Include area code) $225-578-7417$ 
7. PERFORMING ORGANIZATION NAME(S) AND ADDRESS(ES) (continued)

Environmental Laboratory

U.S. Army Engineer Research and Development Center

646 Cajundome Blvd., Suite 301

Lafayette, LA 70506

Environmental Laboratory

U.S. Army Engineer Research and Development Center

Wetlands and Environmental Technologies Research Facility

Louisiana State University - Military Sciences Building

Baton Rouge, LA 70803

Environmental Laboratory U.S. Army Engineer Research and Development Center Joint Airborne Lidar Bathymetry Technical Center of Expertise

Kiln, MS 39556 